\title{
Relationship between Correlations and Volatilities of Global Equity Returns: An Empirical Study of the Eurozone Debt Crisis
}

\author{
Jung-Lieh Hsiao ${ }^{1}$, Hsueh-Ling $\mathrm{Wu}^{2} \&$ Yu-Tzu Wang ${ }^{1}$ \\ ${ }^{1}$ Graduate Institute of International Business, National Taipei University, Taiwan, ROC \\ ${ }^{2}$ Department of Finance and Cooperative Management, National Taipei University, Taiwan, ROC \\ Correspondence: Jung-Lieh Hsiao, Professor of Graduate Institute of International Business, National Taipei \\ University, No. 151, University Road, Sanhsia District, New Taipei, 23701, Taiwan, ROC. Tel: 886-2-2674-8189 \\ ext.66877.E-mail: jhsiao@mail.ntpu.edu.tw
}

Received: December 25, 2013

Accepted: April 1, 2014

Online Published: May 27, 2014

doi: 10.5539/ibr.v7n6p30

URL: http://dx.doi.org/10.5539/ibr.v7n6p30

\begin{abstract}
The objective of this study was to investigate the relationship between correlations of global equity returns and volatilities, in which equity markets are divided into two areas: one is PIIGS area (Portugal, Italy, Ireland, Greece and Spain) and the other is non-PIIGS area. Weekly index prices are collected spanning from January 5, 2001 to January 27, 2012, a total of 578 observations. Current study firstly used the best-fitted ARMA-GARCH model on each stock market and then utilized the diagonal AG-DCC model to derive the dynamic conditional correlations. The empirical finding suggests an overall regional factor denoted by PIIGS volatility (or volatility ratio) and a global factor by the U.S. counterpart during the Eurozone debt crisis. The finding of negative correlation between correlations and volatilities (or volatility ratio), mainly attributed to the PIIGS, is not in line with that of Cappiello, Engle, and Sheppard (2006). Moreover, the correlations of Germany with the other equity markets are not explained by the regional factor but by the global factor. The reason is that Germany has been the Europe's most powerful economy and also plays a pivotal role in the management of Eurozone debt crisis. Lastly, investors may gain benefits from international diversification investment by including assets of PIIGS as well as either the Asian or the developed stock markets.
\end{abstract}

Keywords: PIIGS, diagonal AG-DCC model, dynamic conditional correlations, Eurozone debt crisis

\section{Introduction}

Equity stocks have been one of the famous investment instruments, and many different research aspects of them have been overwhelmingly examined. For example, relationships between/among the equity markets have long been of interest to scholars and financial institutions. Besides, issues such as asset allocation strategy, risk diversification and cross-market hedging are also discussed in bulk by the financial community. Although study of the relationship between equity markets has been conducted for a long time, there seems to be little study on the effect of Eurozone debt crisis on the correlations between stock markets.

There have been increasingly interactions among global stock markets, especially for the periods of significant international events such as the Asian financial crisis (1997), dot-com bubble (2001), financial turmoil caused by the subprime mortgage (2007), and most recently the Eurozone debt crisis. All of these events not only attack the U.S. market and the European market, but also bring significant shocks on the other financial markets. It implies that when financial crisis happens, the influences are not only on a single country, but on the regional or the whole world as well. The work of Forbes and Rigobon (2002) found the structural shocks about the Asian financial crisis, meaning there was a significant co-movement phenomenon in the equity markets during the study period. Besides, the correlation between financial instruments can play a reference vehicle to help investors make their investment or develop related hedging strategies. The change in correlation between financial assets reflects to some degree the change in financial environments and policies. Furthermore, the correlation has brought some hints to individual investors and fund managers on asset allocation and risk diversification.

The main purpose of this study is to explore whether the Eurozone debt crisis throws impacts on correlations of stock market returns. First of all, this study is to derive the dynamic correlations between global equity markets. 
Then we divide the sample countries into two areas: one is the area of Portugal, Italy, Ireland, Greece and Spain (thereafter, PIIGS area identified from the Morgan Stanley Capital International (MSCI)) and the other is non-PIIGS area. Thus, we can go further to explore the effect of Eurozone debt crisis on correlations between equity markets under the circumstance where the U.S. market may still play a role of world information center. These analyses will be conducted through univariate ARMA GARCH $(1,1)$ model and AG-DCC model will be then used to estimate the correlations between equity markets. Lastly, the study will discuss the relationship between PIIGS area and non-PIIGS area, in terms of correlation and volatility. To retard the problem of nonsynchronous trading, weekly data are thus used spanning from January 5, 2001 to January 27, 2012, a total of 577 observations.

The remainder of this paper is planned as the following. Involved in Section two is the literature review. Research methodologies of the Autoregressive Conditional Heteroskedasticity (ARCH) family and DCC-type models are discussed in Section three. In Section four empirical results are presented including analysis of time series data and several econometric models. Finally, conclusions and suggestions are drawn in the last Section.

\section{Literature Review}

This study reviews the related literature, which mainly includes the overview of the linkage between returns of global markets, the background of volatility model in theoretical sense, and the correlation dynamics based on the volatility models.

\subsection{The Correlation between Markets}

There is much literature concerning correlation between different financial markets. Fleming, Kirby, and Ostdiek (1998) compared hedging on cross-market which includes equity, bond and money market with daily returns. Their finding indicates that the stock and bond markets were linked together and had spillover on each other. Longin and Solnik (2001) explained the effect of asymmetry in the global equity markets. They found changes in the correlation on the different markets. Also, Bekaert and Grenadier (2001) and Mamaysky (2002) considered the regular structural economic model in joint stock-bond prices. Their study includes affine term structure model, present-value pricing of equities and asset pricing model based on consumption. Ilmanen (2003) investigated the equity and bond market in America and found positive correlations between returns of equity and bond market in the 1990s. Nevertheless, negative correlations were found in early 1930s, later 1950s, and early 2000s, implying that investors could obtain benefits from bond market if they have capital loss in equity market.

Regarding emerging markets, Gupta and Mollik (2008) suggest that correlations between Australia and emerging markets have been changing over time. Syllignakis and Kouretas (2011) use the weekly returns of several emerging stock markets of Central and Eastern Europe and find that there is significant increase in the correlations between the U.S. and Germany and those between Central and Eastern Europe countries in the financial crisis. Moreover, the finding of Samitas and Tsakalos (2013) indicates that the subprime crisis increases the correlation between returns of Greek stock market and seven European stock markets. However, the impact is lower on the correlation during the Greek Crisis.

\subsection{The Volatility Effect between Markets}

David and Veronesi (2001) explored equity and bond markets in returns' volatility and covariance with uncertainty in future earnings and inflation. They estimated the semi-annual and quarterly data to explore the monthly horizon in the model. It exhibits that the uncertain factors are more important than the basis volatility in explaining volatility and covariance. Chordia, Sarkar and Subrahmanyam (2005) investigated the correlation between daily returns of NASDAQ, ten-year T-bond and thirty-year T-bond. The results show a positive relation between correlation and volatility in equity and bond markets when shocks happened such as financial crisis increasing liquidity and volatility of financial markets. Connolly, Stivers, and Sun (2005) studied the correlation between equity and bond returns in the U.S. from 1986 to 2000 and they found that the equity and bond returns exhibited a negative relation between uncertainty and future correlation. In addition, the equity market uncertainty had a significant effect on cross-markets.

\subsection{The Development of the Methodologies-AG-DCC Model}

Engle (1982) was the first to introduce the ARCH model that was specifically designed to model and forecast the conditional volatility behavior. Some years later, Bollerslev (1986) generalized the ARCH as the widely-used General Autoregressive Conditional Heteroskedasticity (GARCH) model. The GARCH model carries the previous volatility term into the ARCH model. It makes a new field in volatility research which has been extensively applied in the financial and economic time series study. What follows is that there are many research 
interests in the asymmetry volatility effect. Nelson (1991) uses different weights in sign residuals, which is famous as EGARCH model. Glosten, Jagannathan and Runkle (1993) expand the GARCH model into GJR-GARCH model which places a dummy variable to grab the negative return in additional impact. Zakoian (1994) discriminates in a threshold to explain different impact of the returns on conditional volatility.

Bollerslev, Engle and Wooldrige (1988) used T-bond, bond and stock returns to find autocorrelation in the conditional variance and covariance matrix. The study puts both financial and economic research into multivariate GARCH models. Moreover, Bollerslev (1990) presents the Constant Conditional Correlation (CCC) model with strict assumption of fixed correlation of variables, which helps to make the estimation process simpler. In addition, Kroner and $\mathrm{Ng}$ (1998) convert several forms of multivariate GARCH models into a more generalized model. They utilized the Asymmetric Dynamic Covariance (ADC) to describe the volatility transmission in returns of equity and bond market. In 2002, Engle dismantled the restriction of CCC model and introduced the Dynamic Conditional Correlation (DCC) model. The predominant feature of DCC model involves less complicated calculation and can describe numerous variables together. With DCC model, a positive correlation ranging from 0.6 to 0.9 was found by investigating daily data of Dow Jones and NASDAQ spanning from 1990 to 2000. Lastly, Cappiello, Engle, and Sheppard (2006) presented the Asymmetric Generalized Dynamic Conditional Correlation (AG-DCC) model to examine the behavior of global equities and government bonds with structural break. Their findings indicate important volatility linkage and increasing correlations in the equity markets during the financial turmoil.

\section{Research Methodologies}

In order to assess the joint relationship between correlation and volatility dynamics and to examine the effect of Eurozone debt crisis on this dynamic relationship, we first utilize the diagonal AG-DCC model to derive the conditional correlation coefficients and then estimate dynamic linkages between correlations and volatilities across countries.

Because there is advantage of the AG-DCC model where it combines the impact of series-specific news and smoothing parameters, and allows for conditional asymmetries in correlation dynamics, we can be easily to derive the dynamic correlations between markets. However, prior to going further, it is empirically required to examine whether the time series data are characterized by ARCH effect. For simplicity, Ljung-Box $Q^{2}$ statistics are employed to confirm the existence of ARCH effect.

The Finance literature has frequently used GARCH-type models to characterize the volatility process of return series. The original ARMA (p, q)-GARCH model is identified as follows:

$$
\begin{aligned}
r_{i . t}= & a_{i, 0}+\sum_{n=1}^{p} a_{n} r_{i, t-n}+\sum_{n=1}^{q} b_{n} \varepsilon_{i, t-n}+\varepsilon_{i, t} \\
h_{i, t} & =\omega_{i, 0}+\alpha_{i, 0} \varepsilon^{2}{ }_{i, t-1}+\beta_{i, 0} h_{i, t-1}
\end{aligned}
$$

where $r_{i . t}$ is the weekly return of equity index from a market $i$ at time $t ; \sum_{n=1}^{p} a_{n} r_{i, t-n}$ and $\sum_{n=1}^{q} b_{n} \varepsilon_{i, t-n}$ represent lagged returns and lagged error terms of equity market return equation, respectively. The optimal lag lengths in the ARMA (p, q) model are determined with the Ljung-Box $Q$ test. It is noted that both $\mathrm{p}$ and $\mathrm{q}$ are non-negative integers with $a_{0}=0$ and $b_{0}=0 . \mathrm{h}_{\mathrm{i}, \mathrm{t}}$ is volatility specification for equity market returns to govern the shocks in dynamic conditional variance. All parameters of conditional variance equation are expected to be non-negative.

For analysis of this paper to be more consistently constructed, each market return series is considered to best-fit one of the following ten univariate GARCH-type models and then in turn the corresponding standardized residuals can be obtained:

Standard GARCH:

$$
h_{t}=\omega+\alpha \varepsilon^{2}{ }_{t-1}+\beta h_{t-1}
$$

Absolute value GARCH (AVGARCH):

$$
h_{t}{ }^{1 / 2}=\omega+\alpha\left|\varepsilon_{t-1}\right|+\beta h_{t-1}{ }^{1 / 2}
$$

Nonlinear GARCH (NARCH):

$$
h_{t}^{\lambda / 2}=\omega+\alpha\left|\varepsilon_{t-1}\right|^{\lambda}+\beta h_{t-1}{ }^{\lambda / 2}
$$

Exponential GARCH (EGARCH): 


$$
\ln \left(h_{t}\right)=\omega+\alpha \frac{\left|\varepsilon_{t-1}\right|}{\sqrt{h_{t-1}}}+\gamma \frac{\varepsilon_{t-1}}{\sqrt{h_{t-1}}}+\beta \ln \left(h_{t-1}\right)
$$

Threshold GARCH (ZARCH):

$$
h_{t}{ }^{1 / 2}=\omega+\alpha\left|\varepsilon_{t-1}\right|+\gamma I\left[\varepsilon_{t-1}<0\right]\left|\varepsilon_{t-1}\right|+\beta h_{t-1}{ }^{1 / 2}
$$

Glosten-Jagannathan-Runkle GARCH (GJR-GARCH):

$$
h_{t}=\omega+\alpha \varepsilon^{2}{ }_{t-1}+\gamma I\left[\varepsilon_{t-1}<0\right] \varepsilon^{2}{ }_{t-1}+\beta h_{t-1}
$$

Asymmetric power GARCH (APARCH):

$$
h_{t}^{\lambda / 2}=\omega+\alpha\left|\varepsilon_{t-1}\right|^{\lambda}+\gamma I\left[\varepsilon_{t-1}<0\right]\left|\varepsilon_{t-1}\right|^{\lambda}+\beta h_{t-1}^{\lambda / 2}
$$

Asymmetric GARCH (AGARCH):

$$
h_{t}=\omega+\alpha\left(\varepsilon_{t-1}+\gamma\right)^{2}+\beta h_{t-1}
$$

Nonlinear asymmetric GARCH (NAGARCH):

$$
h_{t}=\omega+\alpha\left(\varepsilon_{t-1}+\gamma \sqrt{h_{t-1}}\right)^{2}+\beta h_{t-1}
$$

VGARCH:

$$
h_{t}=\omega+\alpha\left[\frac{\varepsilon_{t-1}}{\sqrt{h_{t-1}}}+\gamma\right]^{2}+\beta h_{t-1}
$$

As mentioned earlier, Bollerslev (1990) proposed the constant conditional correlation (CCC) model. And then, Engle (2002) revised and generalized the CCC model into the widely-used dynamic conditional correlation (DCC) model which is a multivariate GARCH estimator. Differences between these two models are that the DCC model is characterized to capture changeable correlations of financial variables over time and is easy to calculate in large covariance matrix. The following is the conditional covariance matrix under dynamic correlation model:

$$
H_{t}=D_{t} R_{t} D_{t}
$$

where $D_{t}=\operatorname{diag}\left\{\sqrt{h_{i, t}}\right\}$ is a $\mathrm{k} \times \mathrm{k}$ diagonal matrix. $\sqrt{\mathrm{h}_{\mathrm{ii}, \mathrm{t}}}$ is the estimated standard deviation resulting from the above-mentioned univariate GARCH models and $\mathrm{R}_{\mathrm{t}}=\left\{\rho_{i j}\right\}_{t}$, which is the time-varying conditional correlation matrix. The conditional covariance matrix takes the underlying form:

$$
\begin{aligned}
& \mathrm{H}_{\mathrm{t}}=\mathrm{D}_{\mathrm{t}} \mathrm{R}_{\mathrm{t}} \mathrm{D}_{\mathrm{t}}=\left[\begin{array}{ccc}
\sqrt{\mathrm{h}_{11, \mathrm{t}}} & \cdots & 0 \\
\vdots & \ddots & \vdots \\
0 & \cdots & \sqrt{\mathrm{h}_{\mathrm{kk}, \mathrm{t}}}
\end{array}\right]\left[\begin{array}{ccc}
\rho_{11} & \cdots & \rho_{1 \mathrm{k}} \\
\vdots & \ddots & \vdots \\
\rho_{\mathrm{k} 1} & \cdots & \rho_{\mathrm{kk}}
\end{array}\right]\left[\begin{array}{ccc}
\sqrt{\mathrm{h}_{11, \mathrm{t}}} & \cdots & 0 \\
\vdots & \ddots & \vdots \\
0 & \cdots & \sqrt{\mathrm{h}_{\mathrm{kk}, \mathrm{t}}}
\end{array}\right] \\
& =\left[\begin{array}{ccc}
\sqrt{\mathrm{h}_{11, \mathrm{t}}} & \cdots & 0 \\
\vdots & \ddots & \vdots \\
0 & \cdots & \sqrt{\mathrm{h}_{\mathrm{kk}, \mathrm{t}}}
\end{array}\right]\left[\begin{array}{ccc}
1 & \cdots & \rho_{1 \mathrm{k}} \\
\vdots & \ddots & \vdots \\
\rho_{\mathrm{k} 1} & \cdots & 1
\end{array}\right]\left[\begin{array}{ccc}
\sqrt{\mathrm{h}_{11, \mathrm{t}}} & \cdots & 0 \\
\vdots & \ddots & \vdots \\
0 & \cdots & \sqrt{\mathrm{h}_{\mathrm{kk}, \mathrm{t}}}
\end{array}\right] \\
& \mathrm{H}_{\mathrm{t}}=\mathrm{D}_{\mathrm{t}} \mathrm{R}_{\mathrm{t}} \mathrm{D}_{\mathrm{t}}=\left[\begin{array}{ccc}
\mathrm{h}_{11, \mathrm{t}} & \cdots & \rho_{1 \mathrm{k}} \sqrt{\mathrm{h}_{11, \mathrm{t}}} \sqrt{\mathrm{h}_{\mathrm{kk}, \mathrm{t}}} \\
\vdots & \ddots & \vdots \\
\rho_{\mathrm{k} 1} \sqrt{\mathrm{h}_{\mathrm{kk}, \mathrm{t}}} \sqrt{\mathrm{h}_{11, \mathrm{t}}} & \cdots & \mathrm{h}_{\mathrm{kk}, \mathrm{t}}
\end{array}\right]=\left[\begin{array}{ccc}
\mathrm{h}_{11, \mathrm{t}} & \cdots & \mathrm{h}_{1 \mathrm{k}, \mathrm{t}} \\
\vdots & \ddots & \vdots \\
\mathrm{h}_{\mathrm{k} 1, \mathrm{t}} & \cdots & \mathrm{h}_{\mathrm{kk}, \mathrm{t}}
\end{array}\right]
\end{aligned}
$$

Prior to estimating parameters of $\mathrm{R}_{\mathrm{t}}$, the standardized residuals are taken in the form of:

$$
\begin{gathered}
\varepsilon_{i, t}=\frac{r_{i, t}}{\sqrt{h_{i i, t}}} \\
Q_{t}=(1-a-b) \bar{P}+a\left(\varepsilon_{t-1} \varepsilon_{t-1}^{\prime}\right)+b Q_{t-1}
\end{gathered}
$$

$\mathrm{Q}_{\mathrm{t}}=\left[\mathrm{q}_{\mathrm{ij}, \mathrm{t}}\right]$ is the time-varying covariance matrix of the standardized residuals $\varepsilon_{\mathrm{t}} \cdot \overline{\mathrm{P}}=\mathrm{E}\left[\varepsilon_{\mathrm{t}} \varepsilon_{\mathrm{t}}^{\prime}\right]$ is the unconditional covariance matrix of $\varepsilon_{\mathrm{t}}$, denoted as long-run correlations. Additionally, $\mathrm{a}$ and $\mathrm{b}$ are nonnegative parameters scalars restricted to $a+b<1$. Thus, the time-varying conditional correlation matrix $R_{t}$ is formulated as 


$$
R_{t}=\left(\operatorname{diag}\left\{Q_{t}\right\}\right)^{-\frac{1}{2}} Q_{t}\left(\operatorname{diag}\left\{Q_{t}\right\}\right)^{-\frac{1}{2}}
$$

where

$$
\begin{gathered}
\left(\operatorname{diag}\left\{Q_{\mathrm{t}}\right\}\right)^{-\frac{1}{2}}=\operatorname{diag}\left[\begin{array}{ccc}
\frac{1}{\sqrt{\mathrm{q}_{11, \mathrm{t}}}} & \cdots & \frac{1}{\sqrt{\mathrm{q}_{1 \mathrm{k}, \mathrm{t}}}} \\
\vdots & \ddots & \vdots \\
\frac{1}{\sqrt{\mathrm{q}_{\mathrm{k} 1, \mathrm{t}}}} & \cdots & \frac{1}{\sqrt{\mathrm{q}_{\mathrm{kk}, \mathrm{t}}}}
\end{array}\right] \\
\mathrm{R}_{\mathrm{t}}=\left[\begin{array}{ccc}
\frac{1}{\sqrt{\mathrm{q}_{11, \mathrm{t}}}} & \cdots & 0 \\
\vdots & \ddots & \vdots \\
0 & \cdots & \frac{1}{\sqrt{\mathrm{q}_{\mathrm{kk}, \mathrm{t}}}}
\end{array}\right]\left[\begin{array}{ccc}
\mathrm{q}_{11, \mathrm{t}} & \cdots & \mathrm{q}_{1 \mathrm{k}, \mathrm{t}} \\
\vdots & \ddots & \vdots \\
\mathrm{q}_{\mathrm{k} 1, \mathrm{t}} & \cdots & \mathrm{q}_{\mathrm{kk}, \mathrm{t}}
\end{array}\right]\left[\begin{array}{ccc}
\frac{1}{\sqrt{\mathrm{q}_{11, \mathrm{t}}}} & \cdots & 0 \\
\vdots & \ddots & \vdots \\
0 & \cdots & \frac{1}{\sqrt{\mathrm{q}_{\mathrm{kk}, \mathrm{t}}}}
\end{array}\right] \\
\mathrm{R}_{\mathrm{t}}=\left[\begin{array}{ccc}
1 & \cdots & \frac{\mathrm{q}_{1 \mathrm{k}, \mathrm{t}}}{\sqrt{\mathrm{q}_{11, \mathrm{t}} \mathrm{q}_{\mathrm{kk}, \mathrm{t}}}} \\
\vdots & \ddots & \vdots \\
\frac{\mathrm{q}_{\mathrm{k} 1, \mathrm{t}}}{\sqrt{\mathrm{q}_{\mathrm{k}, \mathrm{t}} \mathrm{q}_{11, \mathrm{t}}}} & \cdots & 1
\end{array}\right]=\left[\begin{array}{ccc}
1 & \cdots & \rho_{1 \mathrm{k}, \mathrm{t}} \\
\vdots & \ddots & \vdots \\
\rho_{\mathrm{k} 1, \mathrm{t}} & \cdots & 1
\end{array}\right]
\end{gathered}
$$

and expression of each element of matrix $R_{t}$ can be generalized as

$$
\begin{array}{r}
\rho_{i j, t}=\frac{q_{i j, t}}{\sqrt{q_{i i, t} q_{j j, t}}} \\
\mathrm{i}, \mathrm{j}=1,2, \cdots, \mathrm{n} \text { and } \mathrm{i} \neq \mathrm{j}
\end{array}
$$

Take a bivariate case for an example, the time-varying covariance matrix and the correlation matrix are as follows:

$$
\begin{gathered}
{\left[\begin{array}{ll}
\mathrm{q}_{11, \mathrm{t}} & \mathrm{q}_{12, \mathrm{t}} \\
\mathrm{q}_{21, \mathrm{t}} & \mathrm{q}_{22, \mathrm{t}}
\end{array}\right]=(1-\mathrm{a}-\mathrm{b})\left[\begin{array}{ll}
\overline{\mathrm{p}}_{11} & \overline{\mathrm{p}}_{12} \\
\overline{\mathrm{p}}_{21} & \overline{\mathrm{p}}_{22}
\end{array}\right]+\mathrm{a}\left[\begin{array}{l}
\varepsilon_{1, \mathrm{t}-1} \\
\varepsilon_{2, \mathrm{t}-1}
\end{array}\right]\left[\begin{array}{ll}
\varepsilon_{1, \mathrm{t}-1} & \varepsilon_{2, \mathrm{t}-1}
\end{array}\right]+\mathrm{b}\left[\begin{array}{ll}
\mathrm{q}_{11, \mathrm{t}-1} & \mathrm{q}_{12, \mathrm{t}-1} \\
\mathrm{q}_{21, \mathrm{t}-1} & \mathrm{q}_{22, \mathrm{t}-1}
\end{array}\right]} \\
{\left[\begin{array}{ll}
\mathrm{q}_{11, \mathrm{t}} & \mathrm{q}_{12, \mathrm{t}} \\
\mathrm{q}_{21, \mathrm{t}} & \mathrm{q}_{22, \mathrm{t}}
\end{array}\right]=\left[\begin{array}{ll}
(1-\mathrm{a}-\mathrm{b}) \overline{\mathrm{p}}_{11}+\mathrm{a} \varepsilon_{1, \mathrm{t}-1}^{2}+\mathrm{bq}_{11, \mathrm{t}-1} & (1-\mathrm{a}-\mathrm{b}) \overline{\mathrm{p}}_{12}+\mathrm{a} \varepsilon_{1, \mathrm{t}-1} \varepsilon_{2, \mathrm{t}-1}+\mathrm{bq}_{12, \mathrm{t}-1} \\
(1-\mathrm{a}-\mathrm{b}) \overline{\mathrm{p}}_{21}+\mathrm{a} \varepsilon_{1, \mathrm{t}-1} \varepsilon_{2, \mathrm{t}-1}+\mathrm{bq}_{21, \mathrm{t}-1} & (1-\mathrm{a}-\mathrm{b}) \overline{\mathrm{p}}_{22}+\mathrm{a} \varepsilon_{2, \mathrm{t}-1}^{2}+\mathrm{bq} \mathrm{q}_{22, \mathrm{t}-1}
\end{array}\right]}
\end{gathered}
$$

And thus, the correlation coefficient is shown as the following:

$$
\rho_{12, \mathrm{t}}=\frac{\mathrm{q}_{12, \mathrm{t}}}{\sqrt{\mathrm{q}_{11, \mathrm{t}} \mathrm{q}_{22, \mathrm{t}}}}=\frac{(1-\mathrm{a}-\mathrm{b}) \overline{\mathrm{p}}_{12}+\mathrm{a}\left(\varepsilon_{1, \mathrm{t}-1} \varepsilon_{2, \mathrm{t}-1}\right)+\mathrm{bq}_{12, \mathrm{t}-1}}{\sqrt{(1-\mathrm{a}-\mathrm{b}) \overline{\mathrm{p}}_{11}+\mathrm{a} \varepsilon_{1, \mathrm{t}-1}^{2}+\mathrm{bq}_{11, \mathrm{t}-1} \sqrt{(1-\mathrm{a}-\mathrm{b}) \overline{\mathrm{p}}_{22}+\mathrm{aq}_{1, \mathrm{t}-1}^{2}+\mathrm{bq}_{22, \mathrm{t}-1}}}}
$$

The DCC model is estimated by two stages consisting mainly of the univariate GARCH estimates and the correlation estimate, respectively. The parameters are estimated using quasi-maximum likelihood method (QMLE) proposed by Bollerslev and Wooldridge (1992) Under the Gaussian assumption, the log-likelihood value is calculated as:

$$
L(\vartheta)=-\frac{1}{2} \sum_{t=1}^{T}\left[\left(n \log (2 \pi)+\log \left|D_{t}\right|^{2}+r_{t}^{\prime} D_{t}^{-1} D_{t}^{-1} r_{t}\right)+\left(\log \left|R_{t}\right|+\varepsilon_{t}^{\prime} R_{t}^{-1} \varepsilon_{t}-\varepsilon_{t}^{\prime} \varepsilon_{t}\right)\right]
$$

In the year 2006, Cappiello, Engle and Sheppard proposed the asymmetric generalized dynamic conditional correlation (AG-DCC) model. Asymmetries in correlation estimation are augmented in the standard DCC model proposed by Engle (2002). Hence, the correlation evolution equation of traditional DCC model is modified into:

$$
Q_{t}=\left(\bar{P}-A^{\prime} \bar{P} A-B^{\prime} \bar{P} B-G^{\prime} \bar{N} G\right)+A^{\prime} \varepsilon_{t-1} \varepsilon^{\prime}{ }_{t-1} A+G^{\prime} n_{t-1} n_{t-1}^{\prime} G+B^{\prime} Q_{t-1} B
$$

Where $\mathrm{A}, \mathrm{B}$ and $\mathrm{G}$ are $\mathrm{k} \times \mathrm{k}$ parameter matrices, $n_{\mathrm{t}}=\mathrm{I}\left[\varepsilon_{\mathrm{t}}<0\right] \circ \varepsilon_{\mathrm{t}}(\mathrm{I}[\cdot]$ is a $\mathrm{k} \times 1$ indicator function which takes on value 1 if the argument is true and 0 otherwise, while "o" indicates the Hadamard product) and $\overline{\mathrm{N}}=$ $\mathrm{E}\left[n_{t} n_{\mathrm{t}}^{\prime}\right]$. For both $\overline{\mathrm{P}}$ and $\mathrm{N}$, expectations are infeasible and are replaced with sample analogues, that 
is, $T^{-1} \sum_{t=1}^{T} \varepsilon_{t} \varepsilon_{t}^{\prime}$ and $T^{-1} \sum_{t=1}^{T} n_{t} n_{t}^{\prime}$, respectively. If the $\mathrm{k} \times \mathrm{k}$ parameter matrix $\mathrm{G}$ is significant, it means that the period of sample comes with asymmetric effect. Moreover, this study defines the dummy variable equal to 1 when market declines, otherwise 0 . A large amount of literature asserts that bad news can affect the subsequent volatility. The equation exhibited is the AG-DCC model, in which A-DCC is a special case of the AG-DCC model when matrices A, B and G are replace by scalars. The A-DCC model is as follows:

$$
Q_{\mathrm{t}}=\left(\overline{\mathrm{P}}-\mathrm{a}^{2} \overline{\mathrm{P}}-\mathrm{b}^{2} \overline{\mathrm{P}}-\mathrm{g}^{2} \overline{\mathrm{N}}\right)+\mathrm{a}^{2} \varepsilon_{\mathrm{t}-1} \varepsilon_{\mathrm{t}-1}^{\prime}+\mathrm{g}^{2} n_{\mathrm{t}-1} n_{\mathrm{t}-1}^{\prime}+\mathrm{b}^{2} \mathrm{Q}_{\mathrm{t}-1}
$$

Again, if matrices $\mathrm{A}, \mathrm{B}$, and $\mathrm{G}$ are diagonal matrices, then the AG-DCC representation reduces to the following form:

$$
Q_{\mathrm{t}}=\overline{\mathrm{P}} \circ\left(\mathrm{ii}^{\prime}-\mathrm{aa}^{\prime}-\mathrm{bb}^{\prime}\right)-\overline{\mathrm{N}} \circ \mathrm{gg}^{\prime}+\mathrm{aa}^{\prime} \circ \varepsilon_{\mathrm{t}-1} \varepsilon_{\mathrm{t}-1}^{\prime}+\mathrm{gg}^{\prime} \circ n_{\mathrm{t}-1} n_{\mathrm{t}-1}^{\prime}+\mathrm{bb}^{\prime} \circ Q_{t-1}
$$

where $\mathrm{i}$ is a vector of ones; $\mathrm{a}, \mathrm{b}$, and $\mathrm{g}$ are vectors of the $\mathrm{A}, \mathrm{B}, \mathrm{G}$ matrices in which they are diagonal matrices; and the $\circ$ is Hadamard product.

\section{Empirical Results and Analysis}

This section begins with various tests regarding Unit Roots and ARCH effect. We then report the results of univariate GARCH models that fit, based on the Schwarz Bayesian information criterion (SBIC), each of 10 return series for the first stage of the DCC model. Lastly, regression model of relationship between correlation and volatility is proposed and analyzed, when it is augmented with global and regional factors.

\subsection{Data Description}

Fourteen stock indices have been selected for empirical investigation, covering PIIGS (Portugal, Italy, Ireland, Greece and Spain), Australia, Canada, France, Germany, Hong Kong, Japan, Singapore, Taiwan, and United States. The FTSE ALL-World Index Series including the return on a well-diversified investment, and market value is calculated in the value-weighted manner. With global scope, this study uses the weekly frequency to mitigate the problem of nonsynchronous, and the data period spans from January 5, 2001 to January 27, 2012, a total of 578 observations. The weekly return of each market is calculated as

$$
r_{i, t}=\ln \left(P_{i, t} / P_{i, t-1}\right) \times 100
$$

The PIIGS portfolio, as a regional factor, is calculated by following the method of Hashmi and Tay (2007),

$$
R_{r g(P I I G S), t}=\frac{\sum_{j} w_{j, t} r_{j, t}}{\sum_{j} w_{j, t}}, j=\text { each country of PIIGS }
$$

where $\mathrm{R}_{\mathrm{rg}(\mathrm{PIIGS}), \mathrm{t}}$ is the return of portfolio including PIIGS (Portugal, Italy, Ireland, Greece and Spain), $\mathrm{w}_{\mathrm{j}, \mathrm{t}}$ is the market capitalization for country $j$, and the $r_{j, t}$ is the return for country $j$.

The natural logarithms of stock indices with trend are shown in Figures 1 to 10, which are highly unstable and there is a striking price slump around 2010, together with the previously huge one around 2008. In addition, it indicates existence of unit root for each index price based on PP and KPSS unit tests, though they are not shown here.

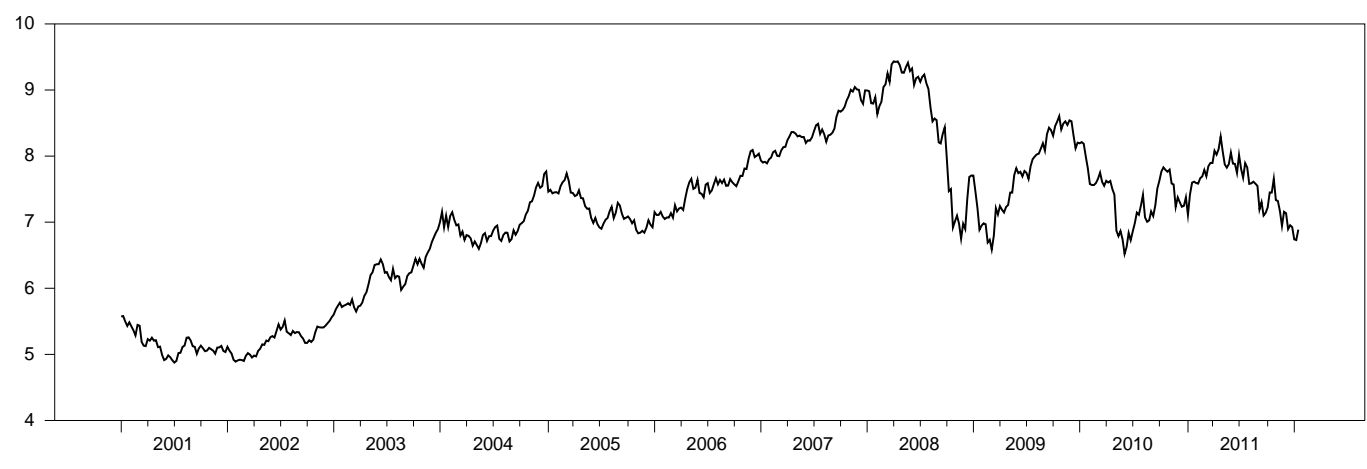

Figure 1 . Stock index trend of $\ln (\mathrm{PIIGS})$ 


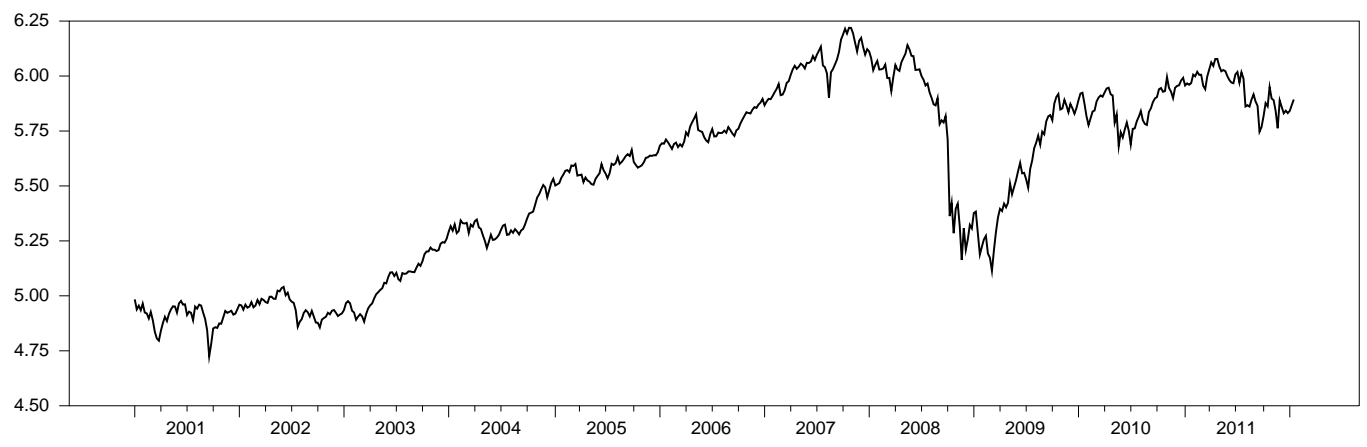

Figure 2. Stock index trend of $\ln$ (Australia)

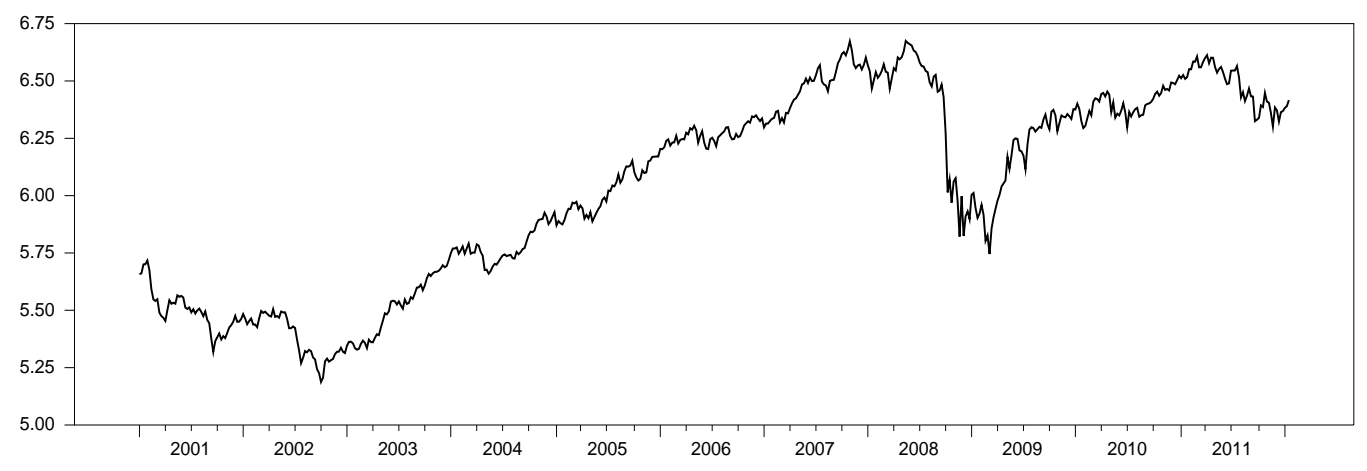

Figure 3. Stock index trend of $\ln ($ Canada)

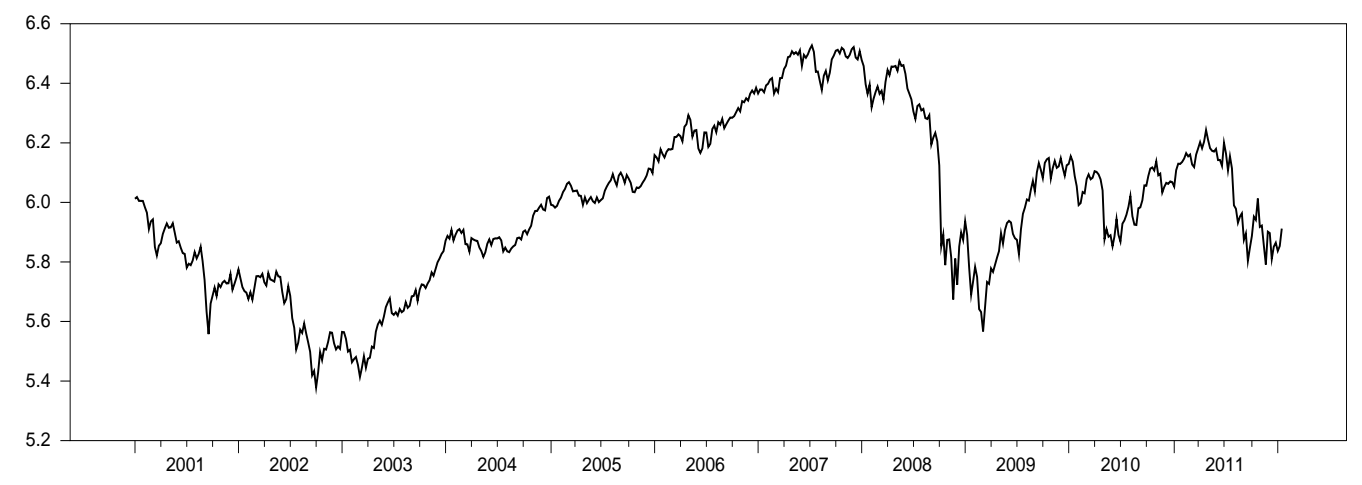

Figure 4. Stock index trend of $\ln$ (France)

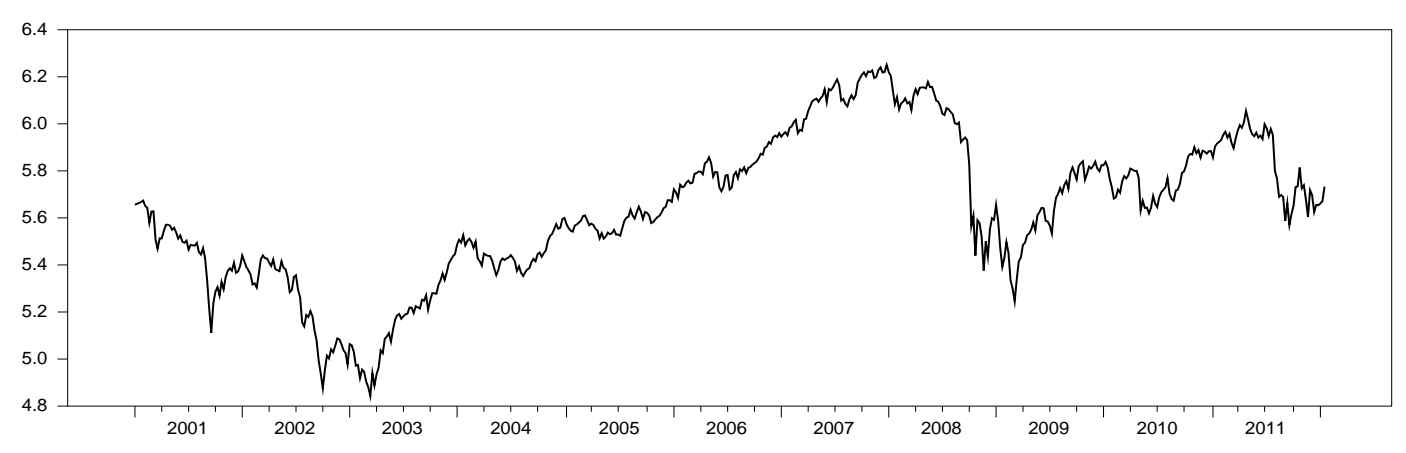

Figure 5. Stock index trend of $\ln$ (Germany) 


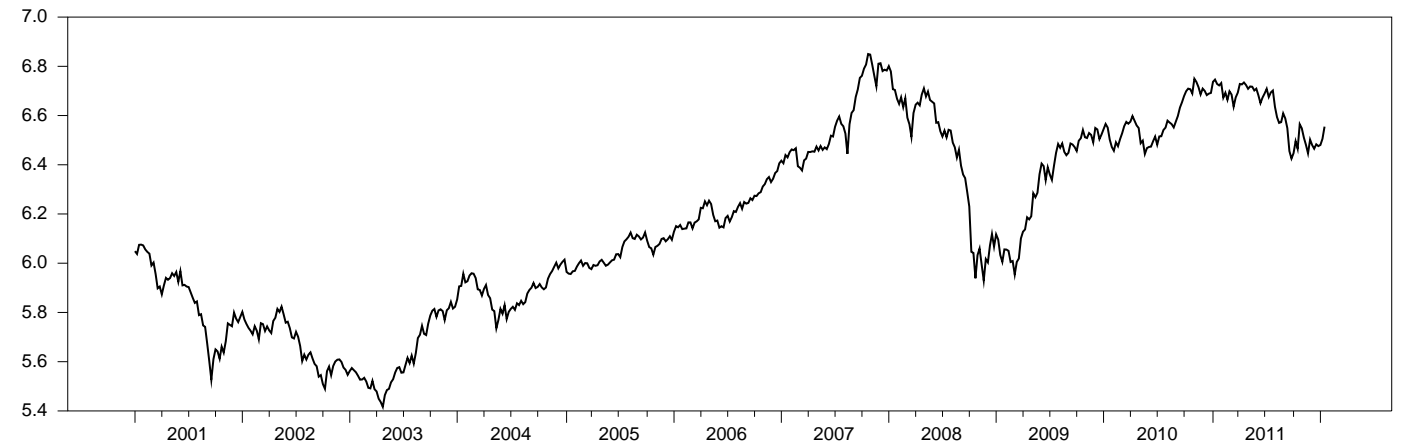

Figure 6. Stock index trend of $\ln$ (Hong Kong)

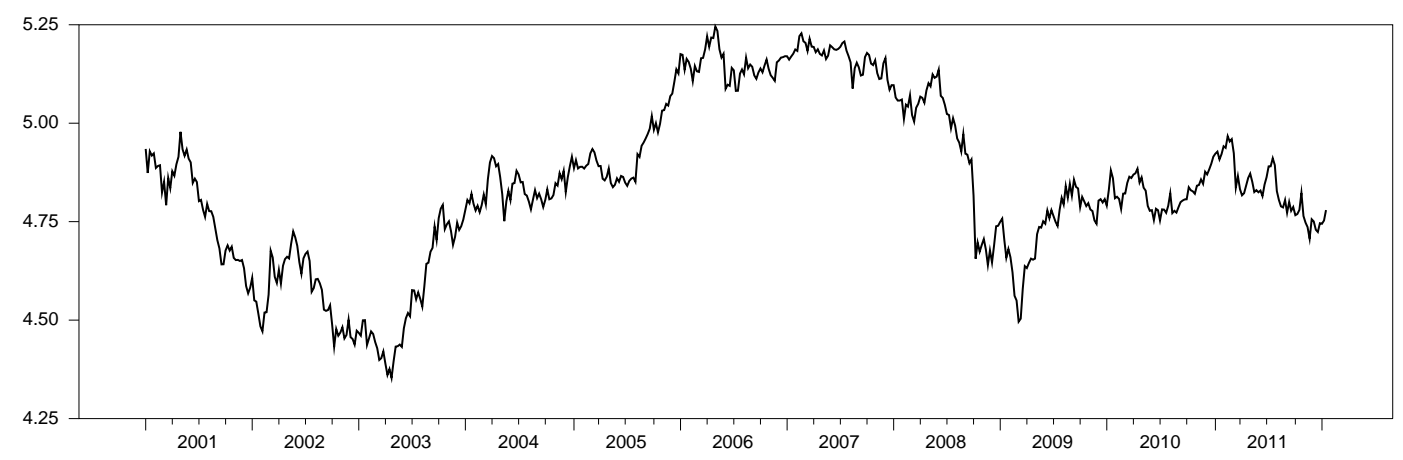

Figure 7. Stock index trend of $\ln ($ Japan)

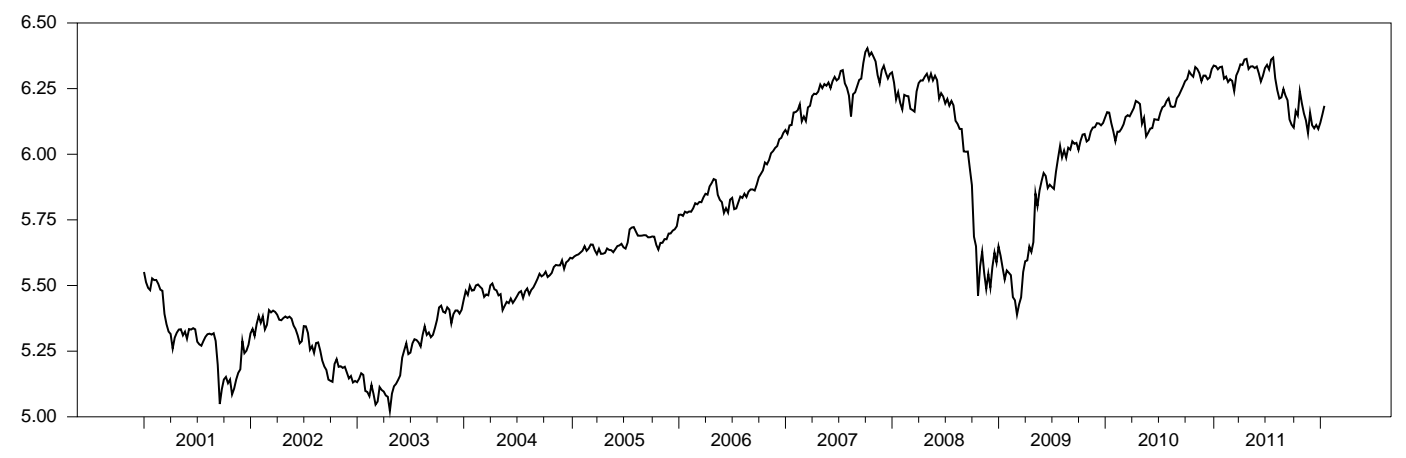

Figure 8. Stock index trend of $\ln$ (Singapore)

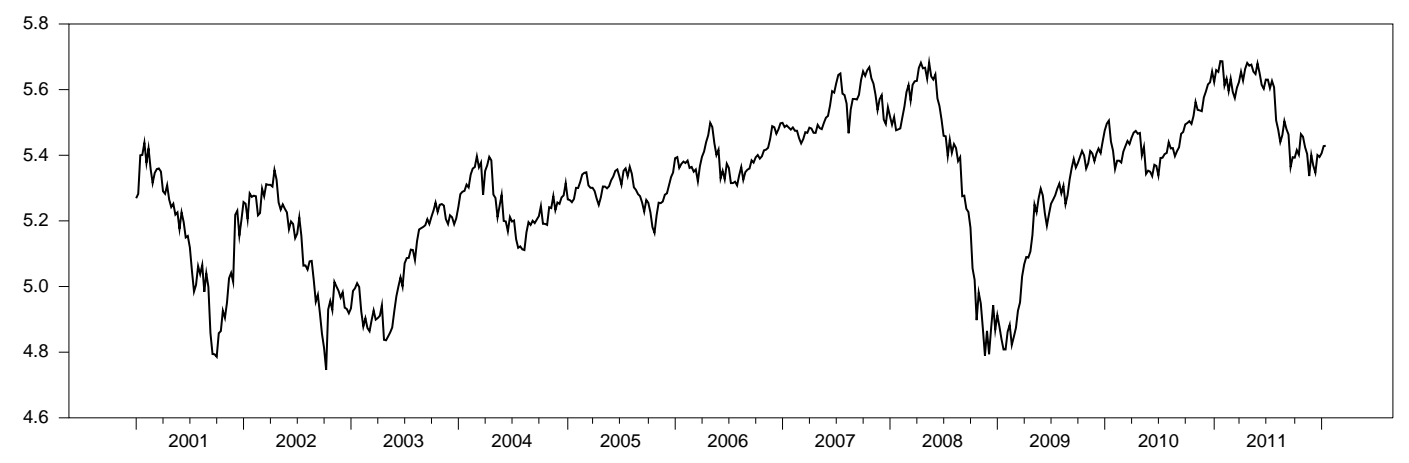

Figure 9. Stock index trend of $\ln$ (Taiwan) 


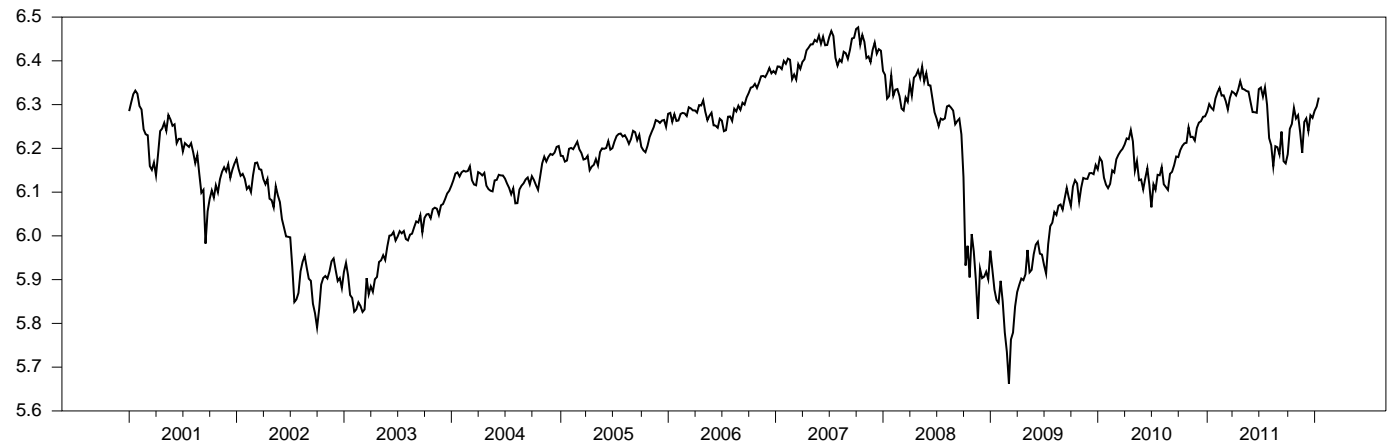

Figure 10. Stock index trend of $\ln ($ United State)

As shown in Table 1, the descriptive statistics show that the average stock return for Australia is the highest and for PIIGS the lowest. Regarding standard deviation, PIIGS has the highest value of 4.0131, while the United States has the lowest value of 2.7248 . All of the weekly stock market returns are significantly and negatively skewed except Taiwan. In addition, all the returns are distributed with kurtosis, indicating the phenomena of fat-tail. Furthermore, Jarque-Bera (JB) test rejects the null hypothesis of normal distribution at $1 \%$ significant level for all the return series.

To visualize the returns for each market, we depict the series in Figures 11 to 20 . The plots show a cluster of larger return volatility, which probably provides the basis of using GARCH-type models to describe the behavior of market returns.

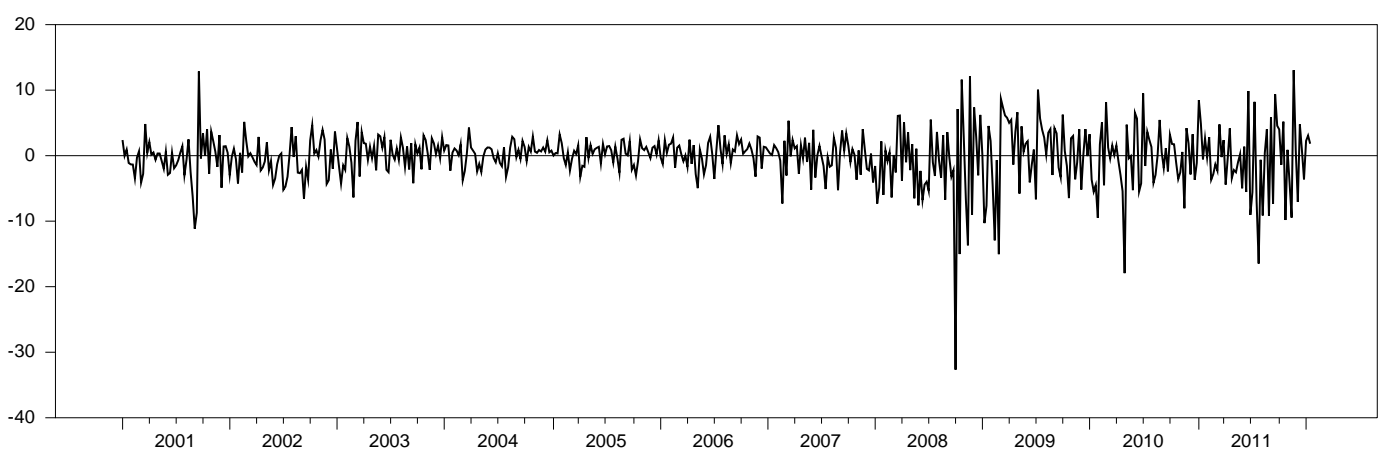

Figure 11. Stock market returns in PIIGS

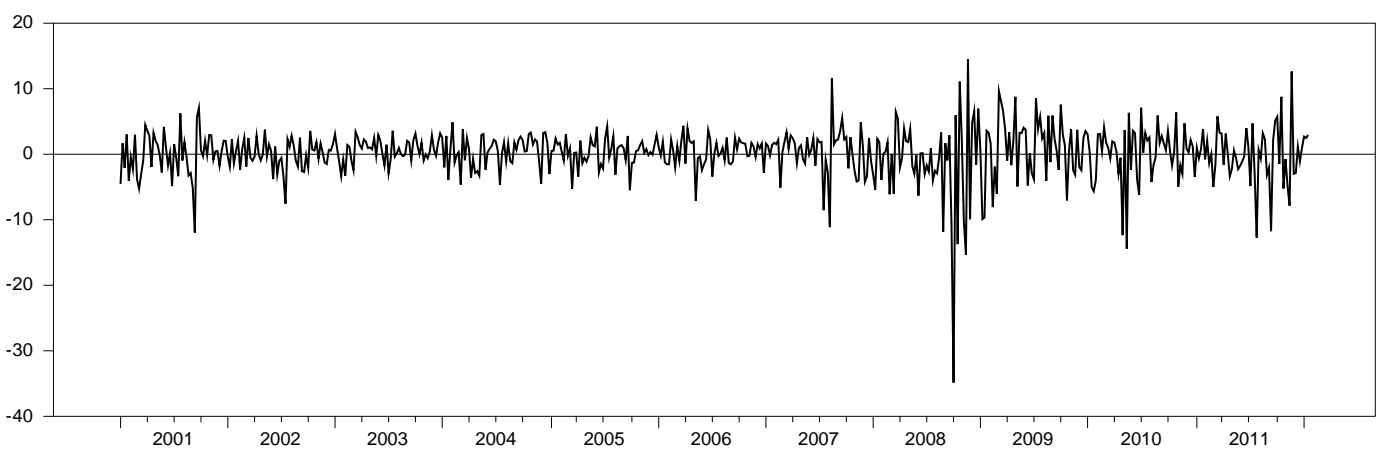

Figure 12. Stock market returns in Australia 


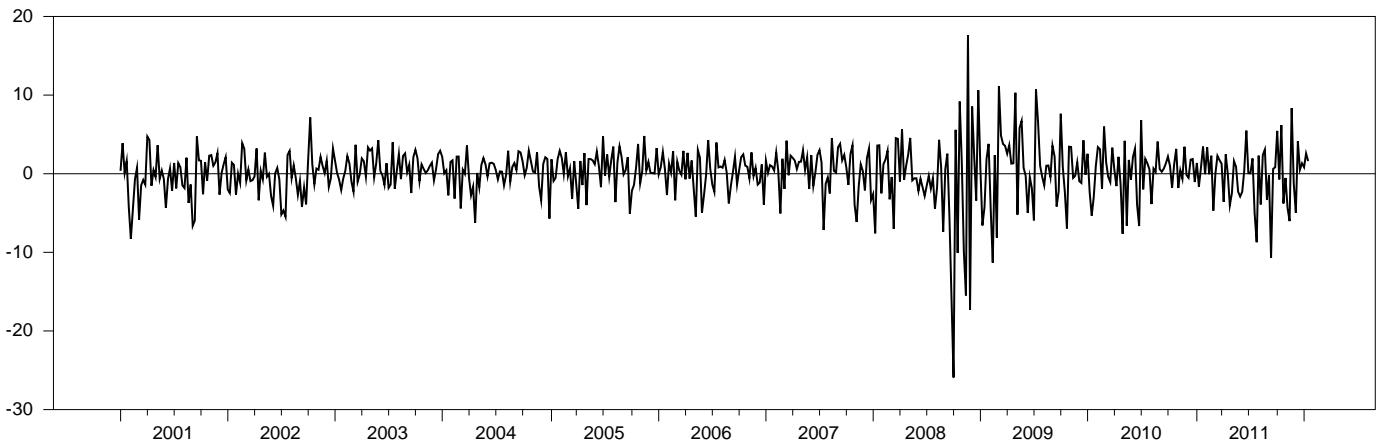

Figure 13. Stock market returns in Canada

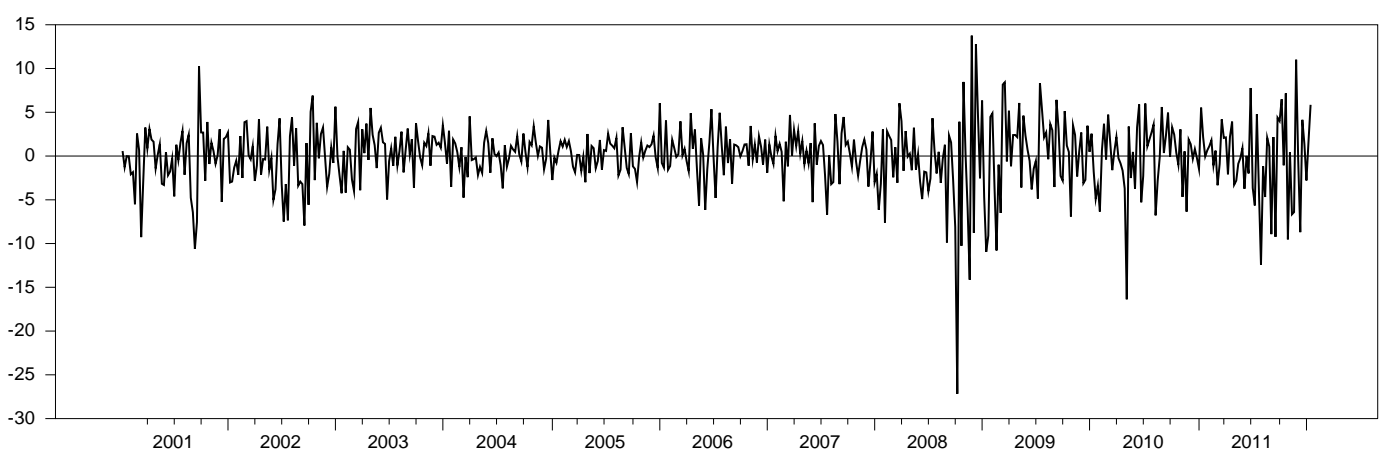

Figure 14. Stock market returns in France

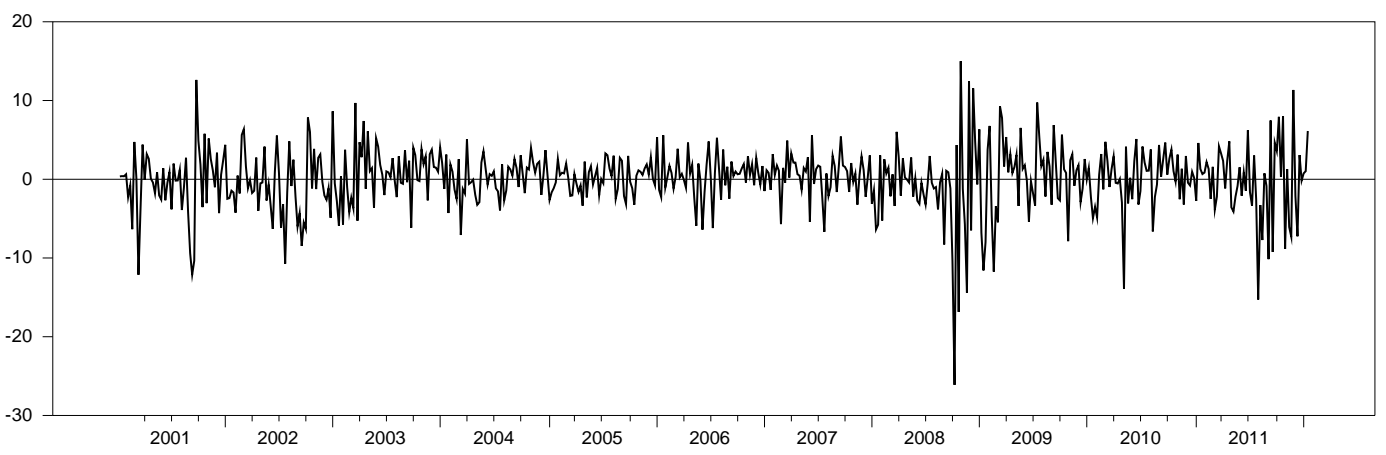

Figure 15. Stock market returns in Germany

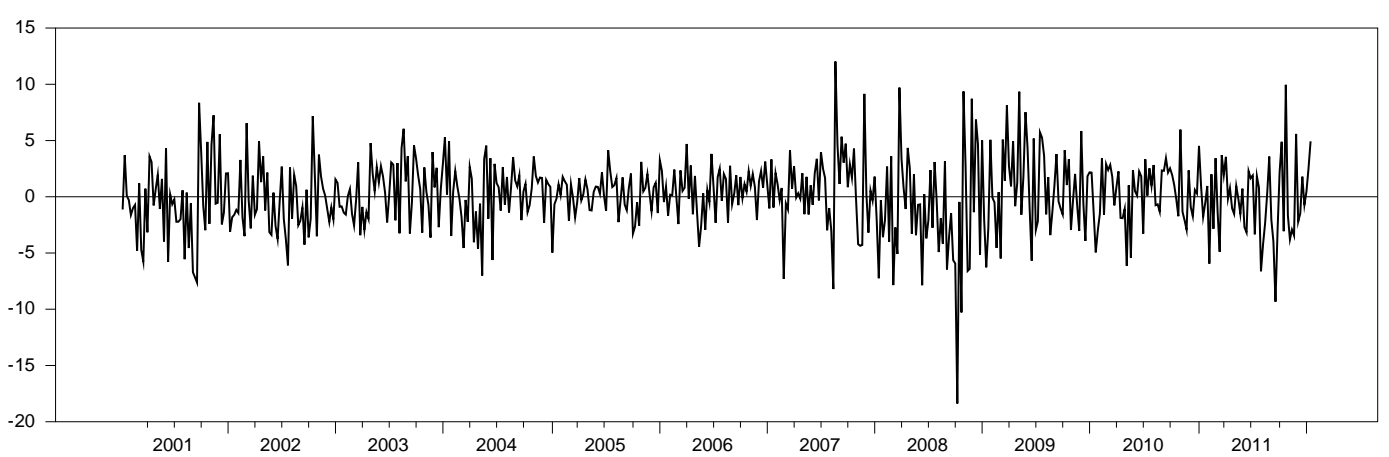

Figure 16. Stock market returns in Hong Kong 


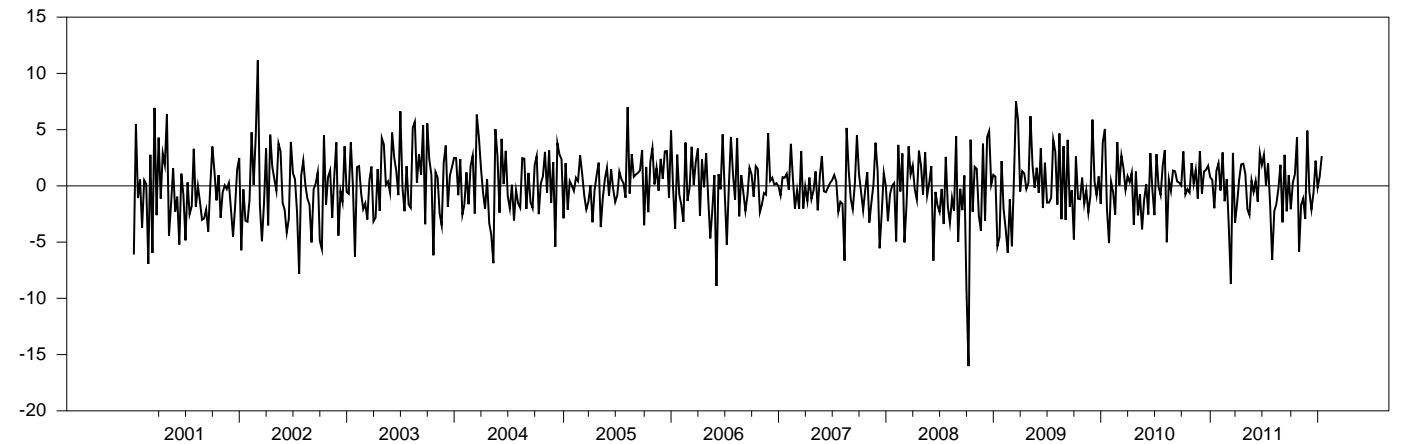

Figure 17. Stock market returns in Japan

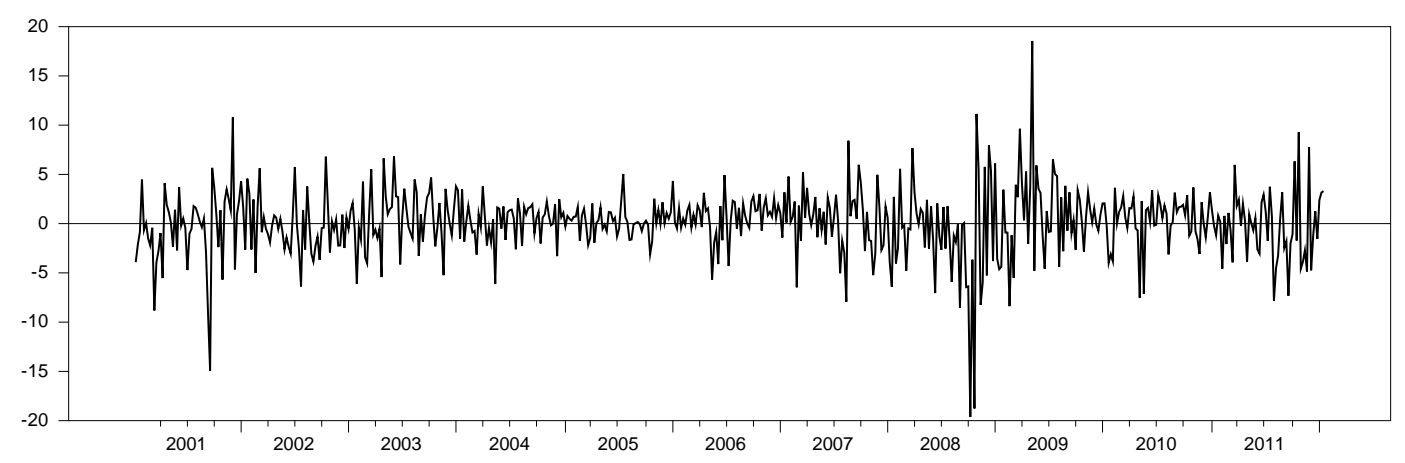

Figure 18. Stock market returns in Singapore

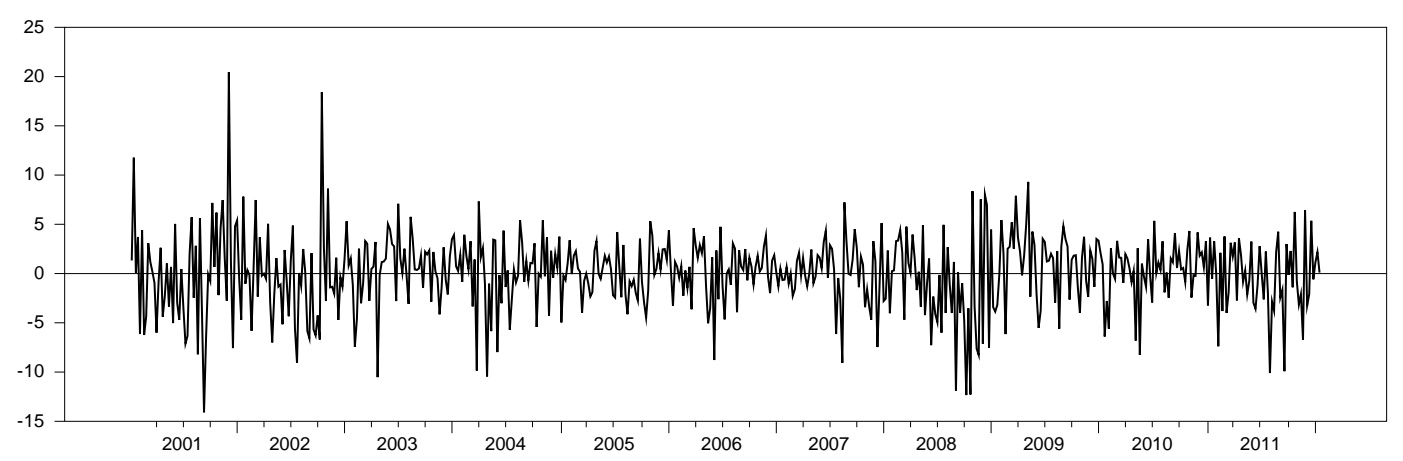

Figure 19. Stock market returns in Taiwan

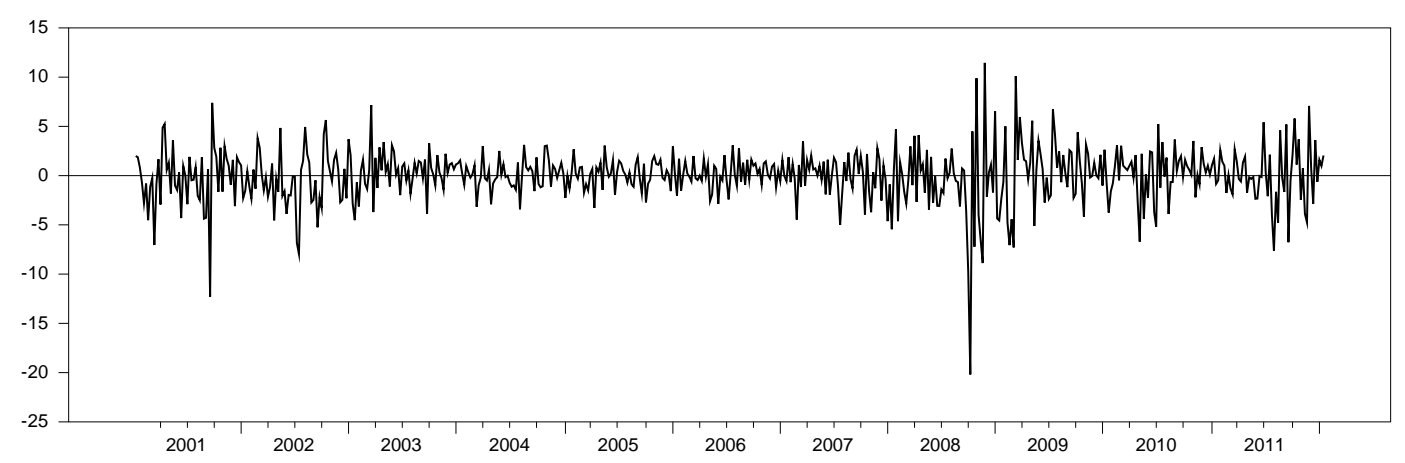

Figure 20. Stock market returns in United State 
Table 1. Descriptive statistics on weekly stock returns

\begin{tabular}{|c|c|c|c|c|c|c|c|c|c|c|c|c|c|c|c|c|c|c|c|c|}
\hline & PIIGS & & $\begin{array}{l}\text { Australia } \\
\text { stocks }\end{array}$ & & $\begin{array}{l}\text { Canada } \\
\text { stocks }\end{array}$ & & $\begin{array}{l}\text { France } \\
\text { stocks }\end{array}$ & & $\begin{array}{c}\text { Germany } \\
\text { stocks }\end{array}$ & & $\begin{array}{c}\text { Hong Kong } \\
\text { stocks }\end{array}$ & & $\begin{array}{l}\text { Japan } \\
\text { stocks }\end{array}$ & & $\begin{array}{l}\text { Singapore } \\
\text { stocks }\end{array}$ & & $\begin{array}{l}\text { Taiwan } \\
\text { stocks }\end{array}$ & & $\begin{array}{c}\text { United States } \\
\text { stocks }\end{array}$ & \\
\hline Mean & -0.1246 & & 0.1627 & & 0.1343 & & -0.0142 & & 0.0181 & & 0.0906 & & -0.0248 & & 0.1171 & & 0.0277 & & 0.0056 & \\
\hline Median & 0.3306 & & 0.5598 & & 0.4597 & & 0.4272 & & 0.4508 & & 0.2239 & & 0.0331 & & 0.3351 & & 0.2671 & & 0.1553 & \\
\hline Maximum & 13.0504 & & 14.5163 & & 17.6090 & & 13.7564 & & 15.0002 & & 12.0277 & & 11.1502 & & 18.5509 & & 20.4396 & & 11.4502 & \\
\hline Minimum & -32.6611 & & -34.8625 & & -25.9150 & & -27.1605 & & -26.1144 & & -18.3843 & & -16.0223 & & -19.6305 & & -14.0862 & & -20.1861 & \\
\hline Std. Dev. & 4.0131 & & 3.8294 & & 3.4998 & & 3.6983 & & 3.9830 & & 3.2100 & & 2.8446 & & 3.3327 & & 3.8080 & & 2.7248 & \\
\hline Skewness & -1.3737 & **** & -1.8204 & $* * *$ & -1.1754 & $* * *$ & -1.0951 & $* * *$ & -0.8901 & $* * *$ & -0.2520 & $* *$ & -0.3570 & $* * *$ & -0.5585 & $* * *$ & -0.0259 & & -0.8535 & $* * *$ \\
\hline Kurtosis & 12.1099 & $* * *$ & 16.6178 & $* * *$ & 11.5253 & $* * *$ & 9.3424 & $* * *$ & 7.8832 & $* * *$ & 5.2688 & $* * *$ & 4.9357 & $* * *$ & 8.8594 & $* * *$ & 5.5929 & $* * *$ & 9.8995 & $* * *$ \\
\hline Jarque-Bera & 2176.6820 & $* * *$ & 4777.1050 & $* * *$ & 1880.2090 & *** & 1082.4470 & $* * *$ & 649.4743 & $* * *$ & 129.8563 & $* * *$ & 102.3364 & $* * *$ & 855.4216 & $* * *$ & 161.7007 & $* * *$ & 1214.5000 & $* * *$ \\
\hline Observations & 577 & & 577 & & 577 & & 577 & & 577 & & 577 & & 577 & & 577 & & 577 & & 577 & \\
\hline
\end{tabular}

Note. Observations for all series in the sample period are 578 . ***,**and * denote statistical significance at the $1 \%, 5 \%$ and $10 \%$ level, respectively. This table reports summary statistics

original data for the 10 Stock Indexes. The software used to estimate the statistics is EViews 6.

\subsection{ARCH Test}

It is necessary to make sure whether time series data are characterized with ARCH effect before going further. After meeting the stationary requirement, the fitted ARMA (p, q) models are obtained for the mean equation of each return series. We use Schwarz Bayesian information criterion (SBIC) to select the optimal lag length, along with Ljung-Box $Q$ statistics to test whether residual terms are serially correlated or not. Table 2 summarizes the results of Ljung-Box $Q$ test. It indicates that there is no serial correlation in the residual terms. In addition, the $\mathrm{ARCH}$ effects are found in the return series, as confirmed by the Ljung-Box $Q^{2}$ statistics. Though not reported here, the Engle and $\mathrm{Ng}$ test also shows a phenomenon of asymmetric effect.

\subsection{The Results of Two-Step AG-DCC Model}

Following Cappiello, Engle, and Sheppard (2006), we selected the best univariate GARCH model for each return series according to the Schwarz Bayesian information criterion (SBIC). Table 3 reports the results of the estimated parameters and the selection of GARCH model. All of the selected GARCH models include a significant asymmetric term which captures the equity return variance of general properties.

As for diagonal AG-DCC model that comes with only $\mathrm{k}$ elements in each coefficient matrix, the results of AG-DCC specifications are presented in Table 4 . All the parameters $b_{i}$ are significant at $1 \%$ level, indicating that GARCH term has an effect on the volatility of stock return. Most of the parameters $a_{i}$ are significant, demonstrating the significant effect of ARCH term on the volatility, while the ARCH terms of Japan and Taiwan stock markets are insignificant. Additionally, asymmetric effects are found in all conditional variance equations at least at $5 \%$ significant level.

Table 2. Results of serial correlation test for ARMA (p, $q)$ models

\begin{tabular}{lclcl}
\hline PIIGS (2,2) & $Q(5)$ & 0.1107 & $Q^{2}(5)$ & $32.3400^{* * *}$ \\
& $Q(10)$ & 12.9429 & $Q^{2}(10)$ & $59.1310^{* * * *}$ \\
\hline Australia(1,0) & $Q(5)$ & 6.1648 & $Q^{2}(5)$ & $46.8786^{* * * *}$ \\
& $Q(10)$ & 15.6704 & $Q^{2}(10)$ & $85.0665^{* * *}$ \\
\hline Canada(1,0) & $Q(5)$ & 2.2649 & $Q^{2}(5)$ & $161.2870^{* * *}$ \\
\hline France(1,0) & $Q(10)$ & 13.9439 & $Q^{2}(10)$ & $339.6332^{* * *}$ \\
\hline Germany $(1,0)$ & $Q(5)$ & 1.3634 & $Q^{2}(5)$ & $55.0480^{* * *}$ \\
& $Q(10)$ & 14.0934 & $Q^{2}(10)$ & $134.1214^{* * *}$ \\
\hline Hong Kong(1,0) & $Q(5)$ & 5.2022 & $Q^{2}(5)$ & $143.1765^{* * *}$ \\
& $Q(10)$ & 15.7429 & $Q^{2}(10)$ & $206.1022^{* * *}$ \\
\hline
\end{tabular}




\begin{tabular}{lcccl}
\hline Japan(1,0) & $Q(5)$ & 0.9305 & $Q^{2}(5)$ & $14.1963 * *$ \\
& $Q(10)$ & 1.3884 & $Q^{2}(10)$ & $19.8431 * *$ \\
\hline Singapore(1,0) & $Q(5)$ & 5.9544 & $Q^{2}(5)$ & $111.1961 * * *$ \\
& $Q(10)$ & 10.2952 & $Q^{2}(10)$ & $132.3342 * * *$ \\
\hline Taiwan(1,0) & $Q(5)$ & 5.1487 & $Q^{2}(5)$ & $30.5304 * * *$ \\
& $Q(10)$ & 8.9923 & $Q^{2}(10)$ & $48.5149 * * *$ \\
\hline United States(1,1) & $Q(5)$ & 7.2998 & $Q^{2}(5)$ & $84.2211^{* * *}$ \\
& $Q(10)$ & 13.3574 & $Q^{2}(10)$ & $119.5722 * * *$
\end{tabular}

Note. $* * * * *$ and $*$ denote statistical significance at the $1 \%, 5 \%$ and $10 \%$ levels, respectively. (.) is the best lag length of ARMA models of each return series and the right hand side of $Q$ (.) is the $Q$ test statistics. The software used is EViews 6.

Table 3. Results of the Univariate GARCH models

\begin{tabular}{llccccccccc}
\hline Asset & Model selected & $\omega$ & & $\alpha$ & & $\gamma$ or & & $\beta$ & \multicolumn{2}{c}{ SBIC } \\
\hline PIIGS & NAGARCH & 0.3404 & $* * *$ & 0.0826 & $* * *$ & -1.7829 & $* * *$ & 0.6533 & $* * *$ & 5.2169 \\
Australia & NAGARCH & 1.0057 & $* * *$ & 0.2020 & $* * *$ & -0.5382 & $* * *$ & 0.6827 & $* * *$ & 5.1908 \\
Canada & GJR-GARCH & 0.7383 & $* * *$ & -0.0005 & & 0.2307 & $* * *$ & 0.7946 & $* * *$ & 5.0122 \\
France & NAGARCH & 0.8177 & $* * *$ & 0.1184 & $* * *$ & -1.1667 & $* * *$ & 0.6667 & $* * *$ & 5.1828 \\
Germany & NAGARCH & 2.0729 & $* * *$ & 0.2279 & $* * *$ & -0.9295 & $* * *$ & 0.4661 & $* * *$ & 5.3214 \\
Hong Kong & NAGARCH & 0.8164 & $* * *$ & 0.1259 & $* * *$ & -0.7750 & $* * *$ & 0.7167 & $* * *$ & 5.0391 \\
Japan & VGARCH & 5.5118 & $* * *$ & 1.2687 & $* * *$ & -0.4900 & $* *$ & 0.1086 & & 4.9436 \\
Singapore & NAGARCH & 0.2890 & $* * *$ & 0.0471 & $* * *$ & -1.5093 & $* * *$ & 0.8183 & $* * *$ & 5.0192 \\
Taiwan & ZARCH & 0.1326 & $* * *$ & 0.0403 & & 0.0731 & $* * *$ & 0.9031 & $* * *$ & 5.4343 \\
United States & AGARCH & -0.0991 & & 0.1531 & $* * *$ & -2.3680 & $* * *$ & 0.7316 & $* * *$ & 4.5272 \\
\hline
\end{tabular}

Note. This table reports the best-fitted univariate GARCH-type model and the estimated parameters. ***, ** and * denote statistical significance at the $1 \%, 5 \%$ and $10 \%$ levels, respectively. The software used is WinRATS Pro7.0.

Table 4. Results of estimated parameters of AG-DCC models

\begin{tabular}{|c|c|c|c|c|c|c|c|c|c|}
\hline Asset & $a_{i}$ & $t$-stat & & $b_{i}$ & $t$-stat & & $g_{i}$ & $t$-stat & \\
\hline PIIGS & 0.0262 & 2.5508 & $* *$ & 0.8056 & 36.1506 & $* * *$ & 0.0617 & 4.5957 & $* * *$ \\
\hline Australia & 0.0059 & 3.2579 & $* * *$ & 0.9195 & 106.4024 & $* * *$ & 0.0168 & 5.6627 & $* * *$ \\
\hline Canada & 0.0140 & 4.4213 & $* * *$ & 0.8874 & 49.2084 & $* * *$ & 0.0179 & 3.1005 & $* * *$ \\
\hline France & 0.0206 & 2.2772 & $* *$ & 0.7866 & 41.9574 & $* * *$ & 0.0672 & 5.3712 & $* * *$ \\
\hline Germany & 0.0154 & 1.7643 & $*$ & 0.7646 & 34.3063 & $* * *$ & 0.0683 & 4.6369 & $* * *$ \\
\hline Hong Kong & 0.0094 & 2.5788 & $* * *$ & 0.9606 & 143.4806 & $* * *$ & 0.0178 & 4.3167 & $* * *$ \\
\hline Japan & $9.8 \mathrm{E}-07$ & 0.0339 & & 0.9868 & 388.5628 & $* * *$ & 0.0322 & 8.6975 & $* * *$ \\
\hline Singapore & 0.0029 & 1.9850 & $* *$ & 0.9690 & 152.4769 & $* * *$ & 0.0124 & 3.4420 & $* * *$ \\
\hline Taiwan & 0.0026 & 0.7799 & & 0.7979 & 22.3584 & $* * *$ & 0.0247 & 2.3885 & $* *$ \\
\hline United States & 0.0278 & 5.8485 & $* * *$ & 0.8986 & 54.2262 & $* * *$ & 0.0168 & 2.7468 & $* * *$ \\
\hline
\end{tabular}

Note. $* * *, * *$ and $*$ denote statistical significance at the $1 \%, 5 \%$ and $10 \%$ levels, respectively. The software used is WinRATS Pro7.0.

\subsection{Volatility and Correlation of Results}

When it comes to empirical discussion on dynamic relationship between the correlation and volatility, we derive 
the dynamic conditional correlations from the estimated results of AG-DCC model and then set up the empirical regression equation by modifying the model of Young and Johnson (2004) as follows.

$$
\begin{aligned}
& \rho_{i, j, t}=\alpha_{i}+\beta_{1} \text { Volatility }_{P I I G S, t}+\beta_{2} \text { Volatility }_{P I I G S, t} \times d_{t}+\beta_{3} \text { Volatility }_{U . S ., t}+\beta_{4} \text { Volatility }_{U . S, t} \times d_{t}+\varepsilon_{i j, t} \\
& \rho_{S, p, t}=\alpha_{i}+\beta_{1} \text { Volatility }_{P I G S, t}+\beta_{2} \text { Volatility }_{P I I G S, t} \times d_{t}+\beta_{3}\left(\text { Volatility }_{\text {PIIGS }, t} / \text { Volatility }_{S, t}\right)+\beta_{4}\left(\text { Volatility }_{P I I G S, t} / \text { Volatility }_{S, t} \times\right.
\end{aligned}
$$

$$
\left.d_{t}\right)+\beta_{5} \text { Volatility }_{U ., . t}+\beta_{6} \text { Volatility }_{U S, t} \times d_{t}+\varepsilon_{s, p, t}
$$

Where $\rho_{\mathrm{i}, \mathrm{j}, \mathrm{t}}$ is the correlation between two stock markets except the PIIGS. $\rho_{\mathrm{s}, \mathrm{p}, \mathrm{t}}$ is the correlation between the PIIGS and the other stock markets. Volatility ${ }_{S, t}$ represents volatility of the stock market returns except the PIIGS, and the Volatility PIISS,$/$ Volatility $_{\mathrm{S}, \mathrm{t}}$ is the ratio of the return volatility of the PIIGS to the return volatility of the stock market $s . \alpha$ is a constant and $\varepsilon_{\mathrm{ij}, \mathrm{t}}\left(\varepsilon_{\mathrm{s}, \mathrm{p}, \mathrm{t}}\right)$ is a random error term at period t. Practitioners in the market frequently use the ratio as a measure of the relative volatility of the two markets. Intuitively, this gives the measure of relative volatility of regional factor to the particular market volatility. Moreover, in the equations

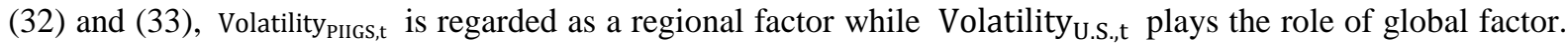
$\mathrm{d}_{\mathrm{t}}$ is the dummy variable for Eurozone debt crisis.

$$
d_{t}=\left[\begin{array}{ll}
1, \text { Dec. } 4,2009 \sim J a n .27,2012 \\
0, & \text { otherwise }
\end{array}\right.
$$

Tables 5 to 9 report the estimated results of equations (32) and (33). They show that in Table 5, volatility ${ }_{\text {PIGS,t }}$ plays a much important role that strengthens relationship for most of the stock markets; however, various correlations with the Germany stock market returns are insignificant to such a regional factor but still subject to the world information center (also referring to Tables 7 and 8). The sign of the coefficients is almost positive, indicating a positive relationship between the correlation and volatility.

Regarding the Eurozone debt crisis, the coefficients of Volatility ${ }_{P I G S, t} \times d_{t}$ are negatively significant for most stock market correlations, but positively significant for Taiwan market (referring to Table 6). It indicates that during the Eurozone debt crisis, regional factor had negative effects on most of the global stock markets but had positive effects on correlation of either Germany or Taiwan with other stock markets. Besides, most correlations with the U.S. are insignificant except Taiwan, meaning that the regional factor did not show any impact on stock markets relating to the U.S. What is more important is that the U.S. factor, that is, Volatility ${ }_{\text {U.S.,t }} \times \mathrm{d}_{\mathrm{t}}$, during the Eurozone debt crisis shows positively significant impacts on most stock markets (that is, only 2 out of 21 cases are negatively influenced, as shown in Table 8). In comparison with PIIGS, the U.S. factor is considered to have larger influence on other stock markets (see Tables 6 and 8). Furthermore, such a systematic finding is reconfirmed by observing Table 9 in which various market correlations with PIIGS can be still explained much more by the U.S. factor with positive impacts.

With particular respect to effect of volatility ratio, Volatility PIIGS, $_{\text {I }} /$ Volatility $_{\mathrm{S}, \mathrm{t}}$, on the correlations between the PIIGS and the other stock markets, it is found positively significant for the Germany, France and the U.S. stock markets, but negatively significant for the Singapore and Taiwan stock markets. In addition, the coefficients of the variable, Volatility PIGS,$/ /$ Volatility $_{\mathrm{s}, \mathrm{t}} \times \mathrm{d}_{\mathrm{t}}$ are all negative and statistically significant to most of the correlations between stock markets, implying that correlation decreases when volatility ratio increases in the period of Eurozone debt crisis. As shown in Gupta and Mollik (2008), the relative volatility of the emerging markets to Australia market is found to influence the change in correlations in some cases. Moreover, the relationship between correlation and relative volatility is much stronger in some emerging country pairs (with Brazil, Chile, India, Malaysia and Philippines) and very weak for Sri Lanka and Turkey. Our study presents the similar finding as well: increasing correlation in some developed country pairs (with Canada, France, Germany Hong Kong, Japan and the U.S.) and no significant correlations in several country pairs (with Australia, Singapore and Taiwan) for the crisis period.

Results of this study implies that reduction in correlations caused by the regional factor in the crisis period opens amounts of opportunities for international diversification with excluding the U.S. in the international portfolio. Gupta and Donleavy (2009) suggest that "investor can reduce their overall portfolio risk by diversifying into equities from other markets as correlation and volatility have negative effect." One explanation similar to the statement of Gupta and Donleavy (2009) is that when crisis happened to the PIIGS area the international capitals flowed from PIIGS into other stock markets, which may induce high relative volatility of PIIGS and thus lead to 
lower or even negative correlations. Moreover, the U.S. factor has a larger positive and significant effect on most of the correlations even in the Eurozone crisis period (referring to Tables 6,8 and 9), which is similar to the finding of Samitas and Tsakalos (2013). They evidenced that whether during the Eurozone debt crisis or not, the influence of the US stock market on the other countries' markets was more important than PIIGS market on the other countries' markets.

Based on the above findings, most of the correlations between stock market returns are negatively affected by regional factor, PIIGS, during the European crisis period, which is not in line with that of Cappiello, Engle, and Sheppard (2006). Their findings indicated increasing correlations in the global equity markets during the financial turmoil. At last, it has been largely found that countries being in high level of development (e.g., developed countries) usually have higher correlations with crisis-originating country (Valls \& Chulia, 2012). In contrast, one of our results regarding Germany stock market does not seem to fully support this phenomenon, which we think is an interesting finding. Several reasons are that Germany has been the Europe's most powerful economy and also plays a pivotal role in the management of Eurozone debt crisis.

To sum up, one implication of negative correlations during the period of Eurozone debt crisis is that we may benefit from international diversification and even gain more benefits when forming an international investment portfolio including assets from PIIGS and either Asian countries such as Japan and Hong Kong or developed countries such as United States, Canada, France and Germany. However, this sort of international portfolio could bring lots amount of diversification only when the volatility ratio of PIIGS to the other countries increases. Another interesting finding is that several two-country market portfolios (e.g., Australia-Canada, Hong Kong-Japan, Japan-Singapore etc.) can be possibly made to gain benefit of diversification only when volatility of PIIGS increases in the crisis period.

Table 5. Results of regression estimate of the coefficient of Volatility PIGS,t

Regression Equation:

\begin{tabular}{|c|c|c|c|c|c|c|c|c|c|c|c|c|c|c|c|}
\hline$\beta_{1}$ & Canada & & France & & Germany & Hong Kong & & Japan & & Singapore & & Taiwan & & United States & \\
\hline \multirow[t]{2}{*}{ Australia } & 0.0006 & & 0.0008 & & 0.0002 & 0.0016 & & 0.0019 & & 0.0007 & & -0.0001 & & 0.0007 & \\
\hline & $(6.3195)$ & $* * *$ & $(4.4238)$ & $* * *$ & (1.1493) & $(9.8454)$ & *** & $(7.2683)$ & $* * *$ & (7.3644) & **** & $(-1.3585)$ & & (3.9073) & $* * *$ \\
\hline \multirow[t]{2}{*}{ Canada } & & & 0.0002 & & $-8.5 \mathrm{E}-06$ & 0.0009 & & 0.0009 & & 0.0007 & & 0.0001 & & 4.6E-05 & \\
\hline & & & (1.7992) & * & $(-0.0516)$ & (7.1813) & **** & (5.3373) & *** & $(6.9107)$ & *** & (1.3281) & & $(0.2604)$ & \\
\hline \multirow[t]{2}{*}{ France } & & & & & $2.2 \mathrm{E}-05$ & 0.0006 & & 0.0011 & & 0.0003 & & 0.0004 & & -0.0003 & \\
\hline & & & & & $(0.4958)$ & $(4.3134)$ & $* * *$ & $(4.4616)$ & $* * *$ & $(1.9176)$ & * & $(2.1256)$ & ** & $(-1.9969)$ & $* *$ \\
\hline \multirow[t]{2}{*}{ Germany } & & & & & & $1.3 \mathrm{E}-05$ & & 0.0002 & & -0.0001 & & 0.0002 & & -0.0004 & \\
\hline & & & & & & $(0.1033)$ & & $(0.8799)$ & & $(-0.8528)$ & & $(1.2181)$ & & $(-2.7033)$ & $* * *$ \\
\hline \multirow[t]{2}{*}{ Hong Kong } & & & & & & & & 0.0016 & & 0.0016 & & -0.0005 & & 0.0007 & \\
\hline & & & & & & & & $(7.8856)$ & *** & $(9.0185)$ & $* * *$ & $(-4.7831)$ & *** & $(3.5513)$ & *** \\
\hline \multirow[t]{2}{*}{ Japan } & & & & & & & & & & 0.0014 & & -0.0004 & & 0.0005 & \\
\hline & & & & & & & & & & $(7.0686)$ & $* * *$ & $(-1.4298)$ & & (3.6538) & $* * *$ \\
\hline \multirow[t]{2}{*}{ Singapore } & & & & & & & & & & & & -0.0002 & & 0.0006 & \\
\hline & & & & & & & & & & & & $(-2.9217)$ & *** & $(4.1549)$ & $* * *$ \\
\hline \multirow[t]{2}{*}{ Taiwan } & & & & & & & & & & & & & & $6.3 \mathrm{E}-05$ & \\
\hline & & & & & & & & & & & & & & $(0.4561)$ & \\
\hline
\end{tabular}

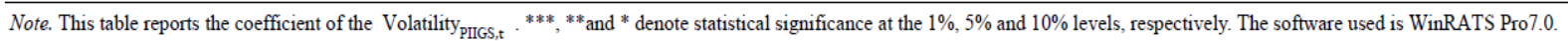


Table 6. Results of regression estimate of the coefficient of Volatility $_{\text {PIIGS,t }} \times d_{t}$

Regression Equation:

$\rho_{i, j, t}=\alpha_{i}+\beta_{1}$ Volatility $_{P I I G S, t}+\beta_{2}$ Volatility $_{P I I G S, t} \times d_{t}+\beta_{3}$ Volatility $_{U . S . t}+\beta_{4}$ Volatility $_{U . S . t} \times d_{t}+\varepsilon_{t}$

\begin{tabular}{|c|c|c|c|c|c|c|c|c|c|c|c|c|c|c|c|}
\hline$\beta_{2}$ & Canada & & France & & Germany & Hong Kong & & Japan & & Singapore & & Taiwan & & United States & \\
\hline \multirow[t]{2}{*}{ Australia } & -0.0007 & & -0.0009 & & 0.0002 & -0.0010 & & -0.0015 & & -0.0006 & & 0.0005 & & 0.0002 & \\
\hline & $(-3.6690)$ & $* * *$ & $(-3.1081)$ & $* * *$ & $(0.7804)$ & $(-2.4484)$ & $* *$ & $(-3.6254)$ & $* * *$ & $(-2.3284)$ & $* *$ & (2.6973) & *** & $(0.5911)$ & \\
\hline \multirow[t]{2}{*}{ Canada } & & & -0.0010 & & 4.1E-05 & -0.0011 & & 0.0000 & & -0.0004 & & 0.0001 & & 0.0004 & \\
\hline & & & $(-3.2509)$ & $* * *$ & (0.1399) & $(-2.9803)$ & *** & $(-0.0825)$ & & $(-1.6446)$ & & $(0.6312)$ & & (1.3126) & \\
\hline \multirow[t]{2}{*}{ France } & & & & & -0.0002 & -0.0003 & & 0.0001 & & -0.0003 & & 0.0001 & & -0.0004 & \\
\hline & & & & & $(-1.4229)$ & $(-0.7767)$ & & $(0.1896)$ & & $(-0.9267)$ & & $(0.2905)$ & & $(-1.4357)$ & \\
\hline \multirow[t]{2}{*}{ Germany } & & & & & & 0.0007 & & 0.0015 & & 0.0007 & & 0.0005 & & $1.7 \mathrm{E}-04$ & \\
\hline & & & & & & (1.9984) & ** & $(2.3448)$ & $* *$ & (2.4303) & ** & (1.4785) & & $(0.6669)$ & \\
\hline \multirow[t]{2}{*}{ Hong Kong } & & & & & & & & -0.0017 & & -0.0006 & & 0.0003 & & -0.0002 & \\
\hline & & & & & & & & $(-5.2958)$ & $* * *$ & $(-2.4046)$ & $* *$ & (1.6688) & * & $(-0.5301)$ & \\
\hline \multirow[t]{2}{*}{ Japan } & & & & & & & & & & -0.0008 & & 0.0007 & & 0.0001 & \\
\hline & & & & & & & & & & $(-2.5940)$ & $* * *$ & $(1.3557)$ & & $(0.2114)$ & \\
\hline \multirow[t]{2}{*}{ Singapore } & & & & & & & & & & & & 0.0004 & & $2.6 \mathrm{E}-05$ & \\
\hline & & & & & & & & & & & & $(2.3207)$ & $* *$ & $(0.1138)$ & \\
\hline \multirow[t]{2}{*}{ Taiwan } & & & & & & & & & & & & & & 0.0005 & \\
\hline & & & & & & & & & & & & & & $(2.7426)$ & $* * *$ \\
\hline
\end{tabular}

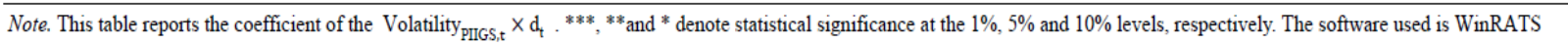
Pro7.0. The numbers are in parentheses are t-statistics with heteroskedasticity-robust standard errors.

Table 7. Regression results of correlation between market return--in the coefficient of Volatility U.S.t $_{\text {t }}$ Regression Equation:

$\rho_{i, j, t}=\alpha_{i}+\beta_{1}$ Volatility $_{P I I G S, t}+\beta_{2}$ Volatility $_{P I I G S, t} \times d_{t}+\beta_{3}$ Volatility $_{U . S . t}+\beta_{4}$ Volatility $_{U . S . t} \times d_{t}+\varepsilon_{t}$

\begin{tabular}{|c|c|c|c|c|c|c|c|c|c|c|c|c|c|c|c|}
\hline$\beta_{3}$ & Canada & France & & Germany & & Hong Kong & & Japan & & Singapore & & Taiwan & & United States & \\
\hline \multirow[t]{2}{*}{ Australia } & -0.0004 & $-2.6 \mathrm{E}-05$ & & 0.0011 & & -0.0016 & & -0.0019 & & -0.0004 & & 0.0013 & & -0.0001 & \\
\hline & $(-1.6828) *$ & $(-0.0548)$ & & $(2.3593)$ & $* *$ & $(-4.5221)$ & $* * *$ & $(-3.1554)$ & $* * *$ & $(-1.7009)$ & $*$ & $(6.0447)$ & $* * *$ & $(-0.2790)$ & \\
\hline \multirow[t]{2}{*}{ Canada } & & 0.0006 & & 0.0012 & & $-4.1 \mathrm{E}-05$ & & -0.0002 & & -0.0002 & & 0.0007 & & 0.0014 & \\
\hline & & $(1.7392)$ & * & $(3.3462)$ & $* * *$ & $(-0.1421)$ & & $(-0.4134)$ & & $(-0.9746)$ & & (3.4536) & $* * *$ & $(3.0071)$ & $* * *$ \\
\hline \multirow[t]{2}{*}{ France } & & & & 0.0003 & & 0.0004 & & -0.0001 & & $-2.0 \mathrm{E}-05$ & & 0.0007 & & 0.0008 & \\
\hline & & & & $(2.7001)$ & $* * *$ & $(1.2023)$ & & $(-0.1308)$ & & $(-0.0478)$ & & (1.7503) & $*$ & $(2.0563)$ & ** \\
\hline \multirow[t]{2}{*}{ Germany } & & & & & & 0.0015 & & 0.0018 & & 0.0008 & & 0.0010 & & 0.0008 & \\
\hline & & & & & & (4.1094) & $* * *$ & $(3.2312)$ & $* * *$ & (1.9939) & $* *$ & (2.5196) & $* *$ & $(2.0784)$ & ** \\
\hline \multirow[t]{2}{*}{ Hong Kong } & & & & & & & & -0.0008 & & -0.0020 & & 0.0012 & & $-2.7 \mathrm{E}-05$ & \\
\hline & & & & & & & & $(-1.8062)$ & $*$ & $(-4.7289)$ & $* * *$ & $(5.0920)$ & $* * *$ & $(-0.0606)$ & \\
\hline \multirow[t]{2}{*}{ Japan } & & & & & & & & & & -0.0014 & & 0.0013 & & -0.0003 & \\
\hline & & & & & & & & & & $(-3.4193)$ & $* * *$ & (1.9651) & $* *$ & $(-0.8964)$ & \\
\hline \multirow[t]{2}{*}{ Singapore } & & & & & & & & & & & & 0.0009 & & -0.0006 & \\
\hline & & & & & & & & & & & & $(4.4147)$ & $* * *$ & $(-1.8182)$ & $*$ \\
\hline \multirow[t]{2}{*}{ Taiwan } & & & & & & & & & & & & & & 0.0003 & \\
\hline & & & & & & & & & & & & & & $(0.7149)$ & \\
\hline
\end{tabular}

Note. This table reports the coefficient of the Volatility U.S.t. $* * *, * *$ and $*$ denote statistical significance at the $1 \%, 5 \%$ and $10 \%$ levels, respectively. The software used is WinRATS Pro 7.0 .

The numbers are in parentheses are $t$-statistics with heteroskedasticity-robust standard errors. 
Table 8. Results of regression estimate of the coefficient of Volatility $_{\text {U.S.,t }} \times d_{t}$

Regression Equation:

$\rho_{i, j, t}=\alpha_{i}+\beta_{1}$ Volatility $_{P I I G S, t}+\beta_{2}$ Volatility $_{P I I G S, t} \times d_{t}+\beta_{3}$ Volatility $_{U . S . t}+\beta_{4}$ Volatility $_{U . S ., t} \times d_{t}+\varepsilon_{t}$

\begin{tabular}{|c|c|c|c|c|c|c|c|c|c|c|c|c|c|c|c|c|}
\hline$\beta_{4}$ & Canada & & France & & Germany & & Hong Kong & & Japan & & Singapore & & Taiwan & & United States & \\
\hline \multirow[t]{2}{*}{ Australia } & 0.0047 & & 0.0054 & & 0.0025 & & 0.0058 & & 0.0012 & & 0.0042 & & 0.0018 & & 0.0034 & \\
\hline & $(7.2466)$ & $* * *$ & $(5.2705)$ & $* * *$ & $(2.2677)$ & ** & (3.8292) & **** & $(0.9043)$ & & (3.8982) & $* * *$ & $(2.2900)$ & $* *$ & (3.2295) & **** \\
\hline \multirow[t]{2}{*}{ Canada } & & & 0.0046 & & 0.0011 & & 0.0049 & & -0.0025 & & 0.0029 & & 0.0031 & & 0.0024 & \\
\hline & & & $(3.8751)$ & $* * *$ & $(1.0022)$ & & (3.3322) & $* * *$ & $(-1.5969)$ & & $(2.7900)$ & $* * *$ & (4.5213) & $* * *$ & $(2.0606)$ & ** \\
\hline \multirow[t]{2}{*}{ France } & & & & & 0.0019 & & 0.0010 & & -0.0032 & & 0.0020 & & 0.0013 & & 0.0020 & \\
\hline & & & & & $(4.2275)$ & **** & $(0.7044)$ & & $(-1.2427)$ & & (1.8249) & * & $(0.9365)$ & & $(2.2138)$ & $* *$ \\
\hline \multirow[t]{2}{*}{ Germany } & & & & & & & -0.0013 & & -0.0052 & & 3.3E-05 & & 0.0008 & & -0.0004 & \\
\hline & & & & & & & $(-0.9128)$ & & $(-2.0785)$ & $* *$ & $(0.0296)$ & & $(0.5663)$ & & $(-0.3940)$ & \\
\hline \multirow[t]{2}{*}{ Hong Kong } & & & & & & & & & 0.0014 & & 0.0036 & & 0.0029 & & 0.0020 & \\
\hline & & & & & & & & & (1.4638) & & (4.1624) & $* * *$ & $(4.2752)$ & $* * *$ & (1.6119) & \\
\hline \multirow[t]{2}{*}{ Japan } & & & & & & & & & & & -0.0002 & & 0.0001 & & -0.0034 & \\
\hline & & & & & & & & & & & $(-0.1843)$ & & $(0.0602)$ & & $(-2.1087)$ & ** \\
\hline \multirow[t]{2}{*}{ Singapore } & & & & & & & & & & & & & 0.0020 & & 0.0017 & \\
\hline & & & & & & & & & & & & & (2.7088) & $* * *$ & (2.1718) & $* *$ \\
\hline \multirow[t]{2}{*}{ Taiwan } & & & & & & & & & & & & & & & 0.0009 & \\
\hline & & & & & & & & & & & & & & & (1.2596) & \\
\hline
\end{tabular}

Note. This table reports the coefficient of the Volatility $\mathrm{US.S,t}_{\mathrm{t}} \times \mathrm{d}_{\mathrm{t}},{ }^{* * * *},{ }^{* *}$ and ${ }^{*}$ denote statistical significance at the $1 \%, 5 \%$ and $10 \%$ levels, respectively. The software used is WinRATS Pro7.0. The numbers are in parentheses are $t$-statistics with heteroskedasticity-robust standard errors.

Table 9. Results of regression estimate of relationship between correlation and volatility (volatility ratio) Regression Equation:

$\rho_{\mathrm{s}, \mathrm{p}, \mathrm{t}}=\alpha_{\mathrm{i}}+\beta_{1}$ Volatility $_{\text {PIGS }, \mathrm{t}}+\beta_{2}$ Volatility $_{\mathrm{PIIS}, \mathrm{t}} \times \mathrm{d}_{\mathrm{t}}+\beta_{3}$ Volatility $_{\mathrm{PIISS}, \mathrm{t}} /$ Volatility $_{\mathrm{S}, \mathrm{t}}+\beta_{4}$ Volatility $_{\text {PIIGS,t}} /$ Volatility $_{\mathrm{S}, \mathrm{t}} \times \mathrm{d}_{\mathrm{t}}$ $+\beta_{5}$ Volatility $_{\text {U.S., }}+\beta_{6}$ Volatility $_{\text {U.S.t. }} \times d_{t}+\varepsilon_{t}$

\begin{tabular}{|c|c|c|c|c|c|c|c|c|c|c|c|c|c|c|c|c|c|c|c|c|}
\hline & $\mathrm{V}_{\text {PIIGS }, \mathrm{t}}$ & & & $V_{\text {PIGS }, t} \times d$ & & & $\mathrm{~V}_{\text {ratio,t }}$ & & & $\mathrm{V}_{\text {ratio, }} \times \mathrm{d}_{\mathrm{t}}$ & & & $\mathrm{V}_{\text {U.S.t.t }}$ & & & $\mathrm{V}_{\mathrm{U} . \mathrm{S}, \mathrm{t}} \times \mathrm{d}_{\mathrm{t}}$ & & & obs & D-W \\
\hline & Coeff. & t-stat & & Coeff. & t-stat & & Coeff. & t-stat & & Coeff. & t-stat & & Coeff. & t-stat & & Coeff. & t-stat & & & \\
\hline Australia & 0.0014 & 7.9263 & $* * *$ & -0.0007 & -1.7010 & $*$ & -0.0130 & -4.5954 & $* * *$ & -0.0012 & -0.2577 & & $5.0 \mathrm{E}-05$ & 0.1214 & & 0.0055 & 4.2005 & $* * *$ & 575 & 0.3043 \\
\hline Canada & 0.0005 & 2.2050 & $* *$ & 0.0013 & 2.2303 & $* *$ & -0.0008 & -0.2595 & & -0.0199 & -4.8558 & $* * *$ & 0.0005 & 0.6492 & & 0.0025 & 1.3851 & & 575 & 0.2111 \\
\hline France & 0.0003 & 1.8921 & * & 0.0008 & 2.2882 & $* *$ & 0.0088 & 2.2803 & $* *$ & -0.0161 & -3.6654 & $* * *$ & 0.0013 & 3.4110 & $* * *$ & 0.0020 & 1.5220 & & 575 & 0.2868 \\
\hline Germany & $-4.6 \mathrm{E}-05$ & -0.2426 & & 0.0006 & 1.7767 & $*$ & 0.0047 & 2.2781 & $* *$ & -0.0138 & -4.6809 & $* * *$ & 0.0011 & 2.2019 & $* *$ & 0.0030 & 2.3694 & $* *$ & 575 & 0.3199 \\
\hline Hong Kong & 0.0010 & 4.0988 & $* * *$ & -0.0008 & -1.6158 & & -0.0007 & -0.2132 & & -0.0120 & -3.2381 & $* * *$ & 0.0002 & 0.3002 & & 0.0051 & 3.0304 & $* * *$ & 575 & 0.2147 \\
\hline Japan & 0.0012 & 5.0877 & $* * *$ & 0.0015 & 1.5752 & & 0.0006 & 0.3524 & & -0.0116 & -1.8440 & * & -0.0006 & -1.8796 & * & -0.0021 & -0.9066 & & 575 & 0.0905 \\
\hline Singapore & 0.0008 & 5.1325 & $* * *$ & 0.0000 & 0.0656 & & -0.0182 & -5.0838 & **** & 0.0017 & 0.4609 & & -0.0001 & -0.3580 & & 0.0034 & 2.8891 & **** & 575 & 0.2280 \\
\hline Taiwan & 0.0010 & 4.7892 & $* * *$ & 0.0011 & 3.0902 & $* * *$ & -0.0293 & -6.0851 & *** & 0.0020 & 0.3644 & & 0.0012 & 3.2553 & $* * *$ & 0.0016 & 1.6687 & $*$ & 575 & 0.3987 \\
\hline United States & 0.0002 & 0.7683 & & 0.0005 & 1.1149 & & 0.0030 & 1.7344 & * & -0.0145 & -7.4312 & **** & -0.0003 & -0.5560 & & 0.0025 & 1.8064 & * & 575 & 0.3495 \\
\hline
\end{tabular}

Note. This table reports the coefficient of the regression model. $d_{t}$ is the dummy variable for Eurozone debt crisis $\left(d_{t}=1\right.$, Dec. $4,2009 \sim$ Jan. 27,2012 . $d_{t}=0$, ow. $)$, and $V_{\text {ratio, }}$ is equal to Volatility $\mathrm{PIGS}_{\mathrm{t}, \mathrm{t}} /$ Volatility $_{\mathrm{S}, \mathrm{t}}{ }^{* * *}, * *$ and ${ }^{*}$ denote statistical significance at the $1 \%, 5 \%$ and $10 \%$ levels, respectively. The software used is WinRATS Pro 7.0 . T-stat comes with 


\section{Conclusions and Suggestions}

This study firstly investigated the dynamic correlation between global stock markets, which are divided into two areas: one is PIIGS (Portugal, Italy, Ireland, Greece and Spain) area and the other is non-PIIGS area. The diagonal version of AG-DCC specification was employed to investigate asymmetries in conditional variances and dynamic correlations of the stock market returns. It was found that the conditional volatility of stock market returns comes with extensive evidence of asymmetry and the correlations of the stock markets change over time.

During the Eurozone debt crisis, most of the correlations between stock markets are negatively affected by the regional factor, meaning that when volatility or volatility ratio increases, correlation will decrease. Investors may gain international diversification by constructing their investment portfolio which includes assets from PIIGS and the other stock markets or from several two-country market portfolios. In addition, the PIIGS relative to the U.S. counterpart plays a role of being more regional factor.

Finally, a lot more countries could be included in the sample and we believe that financial decisions on international investment may be more completely portrayed and easily manipulated. Moreover, Eurozone debt crisis can be alternatively examined in the bond markets and the empirical results may be compared with those found in this study.

\section{References}

Bollerslev, T. (1986). Generalized Autoregressive Conditional Heteroskedasticity. Journal of Econometrics, 31, 307-327. http://dx.doi.org/10.1016/0304-4076 (86)90063-1

Bollerslev, T. (1990). Modeling the Coherence in Short-run Nominal Exchange Rates: A Multivariate Generalized ARCH Model. Review of Economics and Statistics, 72, 498-505. http://dx.doi.org/10.2307/2109358

Bollerslev, T., \& Wooldridge, J. M. (1992). Quasi-maximum likelihood estimation and inference in dynamic models with time-varying covariances. Econometric Reviews, 11(2), 143-172. http://dx.doi.org/10.1080/07474939208800229

Bollerslev, T., Engle, R. F., \& Wooldridge, J. M. (1988). A Capital Asset Pricing Model with Time Varying Covariances. Journal of Political Economy, 96, 116-131. http://dx.doi.org/10.1086/261527

Cappiello, L., Engle, R. F., \& Sheppard, K. (2006). Asymmetric Dynamics in the Correlation of Global Equity and Bond Returns. Journal of Financial Econometrics, 4, 537-572. http://dx.doi.org/10.1093/jjfinec/nbl005

Chordia, T., Sarkar, A., \& Subrahmanyam, A. (2005). An Empirical Analysis of Stock and Bond Market Liquidity. Review of Financial Studies, 18, 85-129. http://dx.doi.org/10.1093/rfs/hhi010

Connolly, R., Stivers, C., \& Sun, L. (2005). Stock Market Uncertainty and the Stock-Bond Return Relation. Journal of Financial and Quantitative Analysis, 40, 161-194. http://dx.doi.org/10.1017/S0022109000001782

David, A., \& Veronesi, P. (2001). Inflation and Earnings Uncertainty and the Volatility of Asset Prices: An Empirical Investigation. Working Paper, University of Chicago.

Engle, R. F. (1982). Autoregressive Conditional Heteroscedasticity with Estimates of the Variance of United Kingdom Inflation. The Econometric Society, 50(4), 987-1007. http://dx.doi.org/10.2307/1912773

Engle, R. F. (2002). Dynamic Conditional Correlation: A Simple Class of Multivariate GARCH Models. Journal of Business and Economic Statistics, 20,339-350. http://dx.doi.org/10.1198/073500102288618487

Engle, R. F., \& Ng, V. K. (1993). Measuring and Testing the Impact of News on Volatility. Journal of Finance, 48, 1749-1778. http://dx.doi.org/10.1111/j.1540-6261.1993.tb05127.x

Fleming, J., Kirby, C., \& Ostdiek, B. (1998). Information and Volatility Linkages in the Stock, Bond, and Money Markets. Journal of Financial Economics, 49, 111-137. http://dx.doi.org/10.1016/S0304-405X(98)00019-1

Forbes, K. J., \& Rigobon, R. (2002). No Contagion, Only Interdependence: Measuring Stock Market Comovements. The Journal of Finance, 57(5), 2223-2261. http://dx.doi.org/10.1111/0022-1082.00494

Glosten, L. R., Jagannathan, R., \& Runkle, D. E. (1993). On the Relation between the Expected Value and the Volatility on the Nominal Excess Returns on Stocks. Journal of Finance, 48, 1779-1801. http://dx.doi.org/10.1111/j.1540-6261.1993.tb05128.x

Grenadier, S. R., \& Bekaert, G. (2001). Stock and Bond Pricing in an Affine Economy. Working Paper, Columbia University. 
Gupta, R., \& Donleavy, D. D. (2009). Benefits of Diversifying Investments into Emerging Markets with Time-varying Correlations: An Australian Perspective. Journal of Multinational Financial Management, 19, 160-177. http://dx.doi.org/10.1016/j.mulfin.2008.10.001

Gupta, R., \& Mollik, A. T. (2008). Volatility, Time Varying Correlation and International Portfolio Diversification: An Empirical Study of Australia and Emerging Markets. International Research Journal of Finance and Economics, 18, 18-37.

Hashimi, A. R., \& Tay, A. S. (2007). Global and Regional Sources of Risk in Equity Markets: Evidence from factor models with time-varying conditional skewness. Journal of Money and Finance, 26, 430-453. http://dx.doi.org/10.1016/j.jimonfin.2007.01.003

Ilmanen, A. (2003). Stock-Bond Correlations. Journal of Fixed Income, 13, 55-66. http://dx.doi.org/10.3905/jfi.2003.319353

Kroner, K. F., \& Ng, V. K. (1998). Modeling Asymmetric Comovements of Asset Returns. The Review of Financial Studies, 11, 817-844. http://dx.doi.org/10.1093/rfs/11.4.817

Longin, F., \& Solnik, B. (2001). Extreme Correlation of International Equity Markets. The Journal of Finance, 56, 649-676. http://dx.doi.org/10.1111/0022-1082.00340

Mamaysky, H. (2002). Market Prices of Risk and Return Predictability in a Joint Stock-Bond Pricing Model. Working Paper No. 2002-25, Yale School of Management.

Nelson, D. B. (1991). Conditional Heteroskedasticity in Asset Returns: A New Approach. Econometrica, 59, 347-370. http://dx.doi.org/10.2307/2938260

Samitas, A., \& Tsakalos, L. (2013). How can a small country affect the European economy? The Greek contagion phenomenon. Journal of International Financial Markets, Institutions and Money, 25, 18-32. http://dx.doi.org/10.1016/j.intfin.2013.01.005

Syllignakis, M., \& Kouretas, G. (2011). Dynamic correlation analysis of financial contagion: evidence from central and eastern European markets. International Review of Economics and Finance, 20(4), 717-732. http://dx.doi.org/10.1016/j.iref.2011.01.006

Valls, N., \& Chulia, H. (2012). Volatility transmission and correlation analysis between the USA and Asia: The impact of the global financial crisis. Global Economic Review, 41(2), 111-129. http://dx.doi.org/10.1080/1226508X.2012.686476

Young, P. J., \& Johnson, R. R. (2004). Bond market volatility vs. stock market volatility: The Swiss Experience. Financial Markets and Portfolio Management, 18, 8-23. http://dx.doi.org/10.1007/s11408-004-0102-4

Zakoian, J. M. (1994). Threshold Heteroskedastic Models. Journal of Economic Dynamics and Control, 18, $931-$ 955. http://dx.doi.org/10.1016/0165-1889(94)90039-6

\section{Copyrights}

Copyright for this article is retained by the author(s), with first publication rights granted to the journal.

This is an open-access article distributed under the terms and conditions of the Creative Commons Attribution license (http://creativecommons.org/licenses/by/3.0/). 